\title{
Effect of Magnetic Field on Nonlinear Absorption of a Strong Electromagnetic Wave in Low-dimensional Systems
}

\author{
Nguyen Quang Bau, Le Thai Hung and Hoang Dinh Trien \\ Hanoi University of Science, Vietnam National University \\ Vietnam
}

\section{Introduction}

Recently, there are more and more interests in studying and discovering the behavior of low-dimensional system, such as compositional superlattices, doped superlattices, quantum wells, quantum wires and quantum dots. The confinement of electrons and phonons in lowdimensional systems considerably enhances the electron mobility and leads to unusual behaviors under external stimuli. Many attempts have conducted dealing with these behaviors, for examples, electron-phonon interaction effects in two-dimensional electron gases (graphene, surfaces, quantum wells) (Ruker et al., 1992; Richter et al., 2009; Butscher et al., 2006). The dc electrical conductivity (Vasilopoulos et al., 1987; Suzuki, 1992), the electronic structure (Sager et al., 2007), the wavefunction distribution (Samuel et al., 2008) and the electron subband (Flores, 2008) in quantum wells have been calculated and analyzed. The problems of the absorption coefficient for a weak electromagnetic wave in quantum wells (Bau\&Phong, 1998), in doped superlattices (Bau et al., 2002) and in quantum wires (Bau et al., 2007) have also been investigated and resulted by using Kubo-Mori method. The nonlinear absorption of a strong electromagnetic wave in low-dimensional systems have been studied by using the quantum transport equation for electrons (Bau\&Trien, 2011). However, the nonlinear absorption of a strong electromagnetic wave in low-dimensional systems in the presence of an external magnetic field with influences of confined phonons is stills open to study. In this chapter, we consider quantum theories of the nonlinear absorption of a strong electromagnetic wave caused by confined electrons in the presence of an external magnetic field in low dimensional systems which considered the effect of confined phonons.

The problem is considered for the case of electron-optical phonon scattering. Analytic expressions of the nonlinear absorption coefficient of a strong electromagnetic wave caused by confined electrons in the presence of an external magnetic field in low-dimensional systems are obtained. The analytic expressions are numerically calculated and discussed to show the differences in comparison with the case of absence of an external magnetic with a specific AlAs/GaAs/AlAs quantum well, a compensated n-p n-GaAs/p-GaAs doped superlattices and a specific GaAs/GaAsAl quantum wire.

This book chapter is organized as follows: In section 2, effect of magnetic field on nonlinear absorption of a strong electromagnetic wave in a quantum well. Section 3 presents the effect 
of magnetic field on nonlinear absorption of a strong electromagnetic wave in a doped superlattice. The effect of magnetic field on nonlinear absorption of a strong electromagnetic wave in a cylindrical quantum wire is presented in section 4 . Conclusions are given in the section 5 .

\section{Effect of magnetic field on nonlinear absorption of a strong electromagnetic wave in a quantum well}

\subsection{The electron distribution function in a quantum well in the presence of a magnetic field with case of confined phonons}

It is well known that in quantum wells, the motion of electrons is restricted in one dimension, so that they can flow freely in two dimensions. In this article, we assume that the quantization direction is in $\mathrm{z}$ direction and only consider intersubband transitions $\left(n \neq n^{\prime}\right)$ and intrasubband transitions $\left(n=n^{\prime}\right)$. As well as, we consider a quantum well with a magnetic field $\vec{B}$ applied perpendicular to its barriers. The Hamiltonian of the confined electron-confined optical phonon system in a quantum well in the presence of an external magnetic field $\vec{B}$ in the second quantization representation can be written as (Mori \& Ando, 1989; Bau \& Phong, 1998; Bau et al, 2009):

$$
\begin{aligned}
& \mathrm{H}=\sum_{\mathrm{n}, \mathrm{N}, \overrightarrow{\mathrm{k}}_{\perp}} \varepsilon_{\mathrm{n}, \mathrm{N}}^{\mathrm{H}}\left(\overrightarrow{\mathrm{k}}_{\perp}-\frac{\mathrm{e}}{\hbar \mathrm{c}} \overrightarrow{\mathrm{A}}(\mathrm{t})\right) \cdot \mathrm{a}_{\mathrm{n}, \mathrm{N}, \overrightarrow{\mathrm{k}}_{\perp}}^{+} \mathrm{a}_{\mathrm{n}, \mathrm{N}, \overrightarrow{\mathrm{k}}_{\perp}}+\sum_{\mathrm{m}, \overrightarrow{\mathrm{q}}_{\perp}} \hbar \omega_{\mathrm{m}, \overrightarrow{\mathrm{q}}_{\perp}} \cdot \mathrm{b}_{\mathrm{m}, \overrightarrow{\mathrm{q}}_{\perp}}^{+} \cdot \mathrm{b}_{\mathrm{m}, \overrightarrow{\mathrm{q}}_{\perp}}+ \\
& +\sum_{n, N, \vec{k}_{\perp}} \sum_{m, \vec{q}_{\perp}} C_{\vec{q}_{\perp}}^{m} I_{n, n^{\prime}}^{m} J_{N, N^{\prime}}(u) a_{n^{\prime}, N^{\prime}, \vec{k}_{\perp}+\vec{q}_{\perp}}^{+} a_{n, N, \vec{k}_{\perp}}\left(b_{m, \vec{q}_{\perp}}+b_{m, \vec{q}_{\perp}}^{+}\right)
\end{aligned}
$$

where $\mathrm{N}$ is the Landau level index $(\mathrm{N}=0,1,2 \ldots) ; \mathrm{n}(\mathrm{n}=1,2,3, \ldots)$ denotes the quantization of the energy spectrum in the $\mathrm{z}$ direction, $\left(n, N, \vec{k}_{\perp}\right)$ and $\left(n^{\prime}, N^{\prime}, \vec{k}_{\perp}+\vec{q}_{\perp}\right)$ are electron states before and after scattering, $\vec{k}_{\perp}\left(\vec{q}_{\perp}\right)$ is the in plane $(x, y)$ wave vector of the electron (phonon), $a_{n, N, \vec{k}_{\perp}}^{+}, a_{n, N, \vec{k}_{\perp}}\left(b_{m, \vec{q}_{\perp}}^{+}, b_{m, \vec{q}_{\perp}}\right)$ are the creation and the annihilation operators of the confined electron (phonon), respectively, $\overrightarrow{\mathrm{A}}(\mathrm{t})$ is the vector potential of an external electromagnetic wave $\overrightarrow{\mathrm{A}}(\mathrm{t})=\mathrm{e} \overrightarrow{\mathrm{E}}_{\mathrm{o}} \sin (\Omega \mathrm{t}) / \Omega$ and $\hbar \omega_{m, \vec{q}_{\perp}}$ is the energy of a confined optical phonon. The electron energy $\varepsilon_{n, N}^{\mathrm{H}}\left(\overrightarrow{\mathrm{k}}_{\perp}\right)$ in quantum wells takes the simple form (Bau et al., 2009):

$$
\varepsilon_{n, N}^{\mathrm{H}}\left(\overrightarrow{\mathrm{k}}_{\perp}\right)=\left(\mathrm{N}+\frac{1}{2}\right) \hbar \Omega_{\mathrm{B}}+\frac{\mathrm{n}^{2} \pi^{2} \hbar^{2}}{2 \mathrm{~m} * \mathrm{~L}^{2}}
$$

where $\Omega_{\mathrm{B}}=\mathrm{eB} / \mathrm{m}^{*}$ is the cyclotron frequency, $\mathrm{m}^{*}$ is the effective mass of electron; $\mathrm{L}$ is the width of quantum wells and $C_{\tilde{\mathrm{q}}_{\perp}}^{m}$ is the electron-phonon interaction factor. In the case of the confined electron- confined optical phonon interaction, we assume that the quantization direction is in $\mathrm{z}$ direction, $\mathrm{C}_{\overrightarrow{\mathrm{q}}_{\perp}}^{\mathrm{m}}$ is:

$$
\left|C_{\bar{q}_{\perp}}^{m}\right|^{2}=\frac{2 \pi e^{2} \hbar \omega_{0}}{\varepsilon_{o} V}\left(\frac{1}{\chi_{\infty}}-\frac{1}{\chi_{0}}\right) \frac{1}{q_{\perp}^{2}+\left(\frac{m \pi}{L}\right)^{2}}
$$

where $\mathrm{V}$, e and $\varepsilon_{o}$ are the normalization volume, the effective charge and the electronic constant (often $\mathrm{V}=1) ; \hbar \omega_{o}$ is the energy of a optical phonon $\left(\hbar \omega_{m, \vec{q}_{\perp}} \approx \hbar \omega_{o}\right) ; \mathrm{m}(\mathrm{m}=1,2, \ldots)$, is 
the quantum number $m$ characterizing confined phonons, $L$ is well's width, $\chi_{\infty}$ and $\chi_{0}$ are the static and the high-frequency dielectric constant, respectively. The electron form factor in case of confined phonons is written as (Rucker et al., 1992):

$$
\mathrm{I}_{\mathrm{nn}}^{\mathrm{m}}=\frac{2}{\mathrm{~L}} \int_{0}^{\mathrm{L}}\left[\eta(\mathrm{m}) \cos \frac{\mathrm{m} \pi \mathrm{z}}{\mathrm{L}}+\eta(\mathrm{m}+1) \sin \frac{\mathrm{m} \pi \mathrm{z}}{\mathrm{L}}\right] \sin \frac{\mathrm{n}^{\prime} \pi \mathrm{z}}{\mathrm{L}} \sin \frac{\mathrm{n} \pi \mathrm{z}}{\mathrm{L}} \mathrm{dz}
$$

with $\eta(\mathrm{m})=1$ if $\mathrm{m}$ is even number and $\eta(\mathrm{m})=0$ if $\mathrm{m}$ is odd number, and $\mathrm{J}_{\mathrm{N}, \mathrm{N}^{\prime}}(\mathrm{u})$ takes the simple form:

$$
J_{N, N^{\prime}}(u)=\int_{-\infty}^{+\infty} \phi_{N^{\prime}}\left(\vec{r}_{\perp}-a_{c}^{2}\left(\vec{k}_{\perp}-\vec{q}_{\perp}\right)\right) e^{i \vec{k}_{\perp} \vec{q}_{\perp}} \phi_{N}\left(\vec{r}_{\perp}-a_{c}^{2} \vec{k}_{\perp}\right) d r
$$

$\vec{r}_{\perp}$ and $\mathrm{a}_{\mathrm{c}}=\mathrm{c} / \mathrm{eB}$ is position and radius of electron in the $(\mathrm{x}, \mathrm{y})$ plane, $\mathrm{e}$ is the electron charge, $c$ is the light velocity, $u=a_{c}^{2} q_{\perp}^{2} / 2, \phi_{N}(x)$ represents the harmonic wave function.

Starting from the Hamiltonian (Eqs. (1-5)) and realizing operator algebraic calculations, we obtain the quantum kinetic equation for confined electrons in the presence of an external magnetic field with case confined phonons:

$$
\begin{aligned}
& \frac{\partial \mathrm{n}_{\mathrm{n}, \mathrm{N}, \mathrm{k}_{\perp}}(\mathrm{t})}{\partial \mathrm{t}}=\left\langle\left[\mathrm{a}_{\mathrm{n}, \ell, \mathrm{N}, \overrightarrow{\mathrm{k}}_{\perp}}^{+} \mathrm{a}_{\mathrm{n}, \ell, \mathrm{N}, \overrightarrow{\mathrm{k}}_{\perp}}, \mathrm{H}\right]\right\rangle_{\mathrm{t}}= \\
& =-\frac{1}{\hbar^{2}} \sum_{n, N, \vec{k}_{\perp}} \sum_{m, \vec{q}_{\perp}}\left|C_{m, \vec{q}_{\perp}}\right|^{2} \cdot\left|I_{n, n^{\prime}}^{m}\right|^{2} \cdot\left|J_{N, N^{\prime}}\left(a_{c}^{2} q_{\perp}^{2} / 2\right)\right|^{2} \cdot \sum_{g, s=-\infty}^{+\infty} J_{g}\left(\frac{e \vec{E}_{o} \vec{q}}{m^{*} \Omega^{2}}\right) \cdot J_{s}\left(\frac{e \vec{E}_{o} \vec{q}}{m^{*} \Omega^{2}}\right) \cdot \exp [i(g-s) \Omega t] \int_{-\infty}^{t} d t^{\prime} \times \\
& \times\left\{\left[\mathrm{n}_{\mathrm{n}, \mathrm{N}, \overrightarrow{\mathrm{k}}_{\perp}}\left(\mathrm{t}^{\prime}\right) \cdot\left(\mathrm{N}_{\mathrm{m}, \overrightarrow{\mathrm{q}}_{\perp}}+1\right)-\mathrm{n}_{\mathrm{n}^{\prime}, \mathrm{N}^{\prime}, \overrightarrow{\mathrm{k}}_{\perp}+\overrightarrow{\mathrm{q}}_{\perp}}\left(\mathrm{t}^{\prime}\right) \cdot \mathrm{N}_{\mathrm{m}, \overrightarrow{\mathrm{q}}_{\perp}}\right]\right. \\
& \times \exp \left\{\mathrm{i}\left(\varepsilon_{\mathrm{n}^{\prime}, \mathrm{N}^{\prime}}^{\mathrm{H}}\left(\overrightarrow{\mathrm{k}}_{\perp}+\overrightarrow{\mathrm{q}}_{\perp}\right)-\varepsilon_{\mathrm{n}, \mathrm{N}}^{\mathrm{H}}\left(\overrightarrow{\mathrm{k}}_{\perp}\right)+\hbar \omega_{\mathrm{m}, \overrightarrow{\mathrm{q}}_{\perp}}-\mathrm{g} \hbar \Omega+\mathrm{i} \hbar \delta\right)\left(\mathrm{t}-\mathrm{t}^{\prime}\right)\right\}+ \\
& +\left[\mathrm{n}_{\mathrm{n}, N, \overrightarrow{\mathrm{k}}_{\perp}}\left(\mathrm{t}^{\prime}\right) \cdot \mathrm{N}_{\mathrm{m}, \overrightarrow{\mathrm{q}}_{\perp}}-\mathrm{n}_{\mathrm{n}^{\prime}, \mathrm{N}^{\prime}, \overrightarrow{\mathrm{k}}_{\perp}+\overrightarrow{\mathrm{q}}_{\perp}}\left(\mathrm{t}^{\prime}\right) \cdot\left(\mathrm{N}_{\mathrm{m}, \overrightarrow{\mathrm{q}}_{\perp}}+1\right)\right] \times \exp \left\{\mathrm{i}\left(\varepsilon_{\mathrm{n}^{\prime}, \mathrm{N}}^{\mathrm{H}}\left(\overrightarrow{\mathrm{k}}_{\perp}+\overrightarrow{\mathrm{q}}_{\perp}\right)-\varepsilon_{\mathrm{n}, \mathrm{N}}^{\mathrm{H}}\left(\overrightarrow{\mathrm{k}}_{\perp}\right)-\hbar \omega_{\mathrm{m}, \overrightarrow{\mathrm{q}}_{\perp}}-\mathrm{g} \hbar \Omega+\mathrm{i} \hbar \delta\right)\left(\mathrm{t}-\mathrm{t}^{\prime}\right)\right\}- \\
& -\left[\mathrm{n}_{\mathrm{n}^{\prime}, \mathrm{N}^{,}, \overrightarrow{\mathrm{k}}_{\perp}-\overrightarrow{\mathrm{q}}_{\perp}}\left(\mathrm{t}^{\prime}\right) \cdot\left(\mathrm{N}_{\mathrm{m}, \overrightarrow{\mathrm{q}}_{\perp}}+1\right)-\mathrm{n}_{\mathrm{n}, \mathrm{N}, \overrightarrow{\mathrm{k}}_{\perp}}\left(\mathrm{t}^{\prime}\right) \cdot \mathrm{N}_{\mathrm{m}, \overrightarrow{\mathrm{q}}_{\perp}}\right] \times \exp \left\{\mathrm{i}\left(\varepsilon_{\mathrm{n}, \mathrm{N}}^{\mathrm{H}}\left(\overrightarrow{\mathrm{k}}_{\perp}\right)-\varepsilon_{\mathrm{n}^{\prime}, N}^{\mathrm{H}}\left(\overrightarrow{\mathrm{k}}_{\perp}-\overrightarrow{\mathrm{q}}_{\perp}\right)+\hbar \omega_{\mathrm{m}, \overrightarrow{\mathrm{q}} \perp}-\mathrm{g} \hbar \Omega+\mathrm{i} \hbar \delta\right)\left(\mathrm{t}-\mathrm{t}^{\prime}\right)\right\}-(6) \\
& \left.-\left[n_{n^{\prime}, N^{\prime}, \vec{k}_{\perp}-\vec{q}_{\perp}}\left(t^{\prime}\right) \cdot N_{m, \vec{q}_{\perp}}-n_{n, N, \vec{k}_{\perp}}\left(t^{\prime}\right) \cdot\left(N_{m, \vec{q}_{\perp}}+1\right)\right] \exp \left\{i\left(\varepsilon_{n, N}^{\mathrm{H}}\left(\vec{k}_{\perp}\right)-\varepsilon_{n^{\prime}, N^{\prime}}^{\mathrm{H}}\left(\vec{k}_{\perp}-\overrightarrow{\mathrm{q}}_{\perp}\right)-\hbar \omega_{\mathrm{m}, \overrightarrow{\mathrm{q}}_{\perp}}-\mathrm{g} \hbar \Omega+\mathrm{i} \hbar \delta\right)\left(\mathrm{t}-\mathrm{t}^{\prime}\right)\right\}\right\}
\end{aligned}
$$

where $\langle\psi\rangle_{\mathrm{t}}$ is the statistical average value at the moment $\mathrm{t}$ and $\langle\psi\rangle_{\mathrm{t}}=\operatorname{Tr}(\hat{\mathrm{W}} \hat{\psi})(\hat{\mathrm{W}}$ being the density matrix operator); $\mathrm{J}_{\mathrm{g}}(\mathrm{x})$ is the Bessel function, $\mathrm{m}^{*}$ is the effective mass of the electron, the quantity $\delta$ is infinitesimal and appears due to the assumption of an adiabatic interaction of the electromagnetic wave; $n_{n, N, \vec{k}_{\perp}}(t)=a_{n, \ell, N, \vec{k}_{\perp}}^{+} a_{n, \ell, N, \vec{k}_{\perp}}$ is electron distribution function in quantum well; $\mathrm{N}_{\mathrm{m}, \overrightarrow{\mathrm{q}} \perp}$ which comply with Bose-Einstein statistics, is the timeindependent component of the phonon distribution function. In the case of the confined electron-confined optical phonon interaction, $\mathrm{N}_{\mathrm{m}, \overrightarrow{\mathrm{q}} \perp}$ can be written as (Abouelaoualim, 1992):

$$
N_{m, \vec{q}_{\perp}}=\frac{1}{e^{\frac{\hbar \omega_{m, q_{\perp}}}{k_{B} T}}-1}
$$


After using the first order tautology approximation method (Malevich\&Epstein, 1974) to solve this equation, the expression of electron distribution function can be written as:

$$
\begin{aligned}
& \mathrm{n}_{\mathrm{n}, \mathrm{N}, \overrightarrow{\mathrm{k}}_{\perp}}(\mathrm{t})=-\sum_{\mathrm{n}, \mathrm{N}, \overrightarrow{\mathrm{k}}_{\perp}} \sum_{\mathrm{m}, \overrightarrow{\mathrm{q}}_{\perp}}\left|\mathrm{C}_{\mathrm{m}, \overrightarrow{\mathrm{q}}_{\perp}}\right|^{2} \cdot\left|\mathrm{I}_{\mathrm{n}, \mathrm{n}^{\prime}}^{\mathrm{m}}\right|^{2} \cdot\left|J_{\mathrm{N}, \mathrm{N}^{\prime}}\right|^{2} \sum_{\mathrm{g}, \mathrm{s}=-\infty}^{+\infty} \mathrm{J}_{\mathrm{g}}\left(\frac{\mathrm{e} \overrightarrow{\mathrm{E}}_{\mathrm{o}} \overrightarrow{\mathrm{q}}}{\mathrm{m}^{*} \Omega^{2}}\right) \cdot J_{\mathrm{g}+\mathrm{s}}\left(\frac{\mathrm{e} \overrightarrow{\mathrm{E}}_{\mathrm{o}} \overrightarrow{\mathrm{q}}}{\mathrm{m}^{*} \Omega^{2}}\right) \cdot \frac{\exp (-\mathrm{is} \Omega \mathrm{t})}{\mathrm{s} \Omega} \times \\
& \times\left\{-\frac{\overline{\mathrm{n}}_{\mathrm{n}, \mathrm{N}, \overrightarrow{\mathrm{k}}_{\perp}} \cdot \mathrm{N}_{\mathrm{m}, \overrightarrow{\mathrm{q}}_{\perp}}-\overline{\mathrm{n}}_{\mathrm{n}^{\prime},,^{\prime}, \mathrm{k}_{\perp}+\overrightarrow{\mathrm{q}}_{\perp}} \cdot\left(\mathrm{N}_{\mathrm{m}, \overrightarrow{\mathrm{q}}_{\perp}}+1\right)}{\varepsilon_{\mathrm{n}^{\prime}, \mathrm{N}^{\prime}}^{\mathrm{H}}\left(\overrightarrow{\mathrm{k}}_{\perp}+\overrightarrow{\mathrm{q}}_{\perp}\right)-\varepsilon_{\mathrm{n}, \mathrm{N}}^{\mathrm{H}}\left(\mathrm{k}_{\perp}\right)-\hbar \omega_{\mathrm{m}, \overrightarrow{\mathrm{q}}_{\perp}}-\mathrm{g} \hbar \Omega+\mathrm{i} \hbar \delta}\right. \\
& -\frac{\overline{\mathrm{n}}_{\mathrm{n}, \mathrm{N}, \overrightarrow{\mathrm{k}}_{\perp}} \cdot\left(\mathrm{N}_{\mathrm{m}, \overrightarrow{\mathrm{q}}_{\perp}}+1\right)-\overline{\mathrm{n}}_{\mathrm{n}^{\prime}, \mathrm{N}^{\prime}, \overrightarrow{\mathrm{k}}_{\perp}+\overrightarrow{\mathrm{q}}_{\perp}} \cdot \mathrm{N}_{\mathrm{m}, \mathrm{q}_{\perp}}}{\varepsilon_{\mathrm{n}^{\prime}, \mathrm{N}^{\prime}}^{\mathrm{H}}\left(\overrightarrow{\mathrm{k}}_{\perp}+\overrightarrow{\mathrm{q}}_{\perp}\right)-\varepsilon_{\mathrm{n}, \mathrm{N}}^{\mathrm{H}}\left(\overrightarrow{\mathrm{k}}_{\perp}\right)+\hbar \omega_{\mathrm{m}, \overrightarrow{\mathrm{q}}_{\perp}}-\mathrm{g} \hbar \Omega+\mathrm{i} \hbar \delta}+ \\
& +\frac{\overline{\mathrm{n}}_{\mathrm{n}^{\prime}, \mathrm{N}^{\prime}, \overrightarrow{\mathrm{k}}_{\perp}-\overrightarrow{\mathrm{q}}_{\perp}} \cdot \mathrm{N}_{\mathrm{m}, \overrightarrow{\mathrm{q}}_{\perp}}-\overline{\mathrm{n}}_{\mathrm{n}, \mathrm{N}, \overrightarrow{\mathrm{k}}_{\perp}} \cdot\left(\mathrm{N}_{\mathrm{m}, \overrightarrow{\mathrm{q}}_{\perp}}+1\right)}{\varepsilon_{\mathrm{n}, \mathrm{N}}^{\mathrm{H}}\left(\overrightarrow{\mathrm{k}}_{\perp}\right)-\varepsilon_{\mathrm{n}^{\prime}, \mathrm{N}^{\prime}}^{\mathrm{H}}\left(\overrightarrow{\mathrm{k}}_{\perp}-\overrightarrow{\mathrm{q}}_{\perp}\right)-\hbar \omega_{\mathrm{m}, \overrightarrow{\mathrm{q}}_{\perp}}-\mathrm{g} \hbar \Omega+\mathrm{i} \hbar \delta} \\
& \left.+\frac{\overline{\mathrm{n}}_{\mathrm{n}^{\prime}, \mathrm{N}^{\prime}, \overrightarrow{\mathrm{k}}_{\perp}-\overrightarrow{\mathrm{q}}_{\perp}} \cdot\left(\mathrm{N}_{\mathrm{m}, \overrightarrow{\mathrm{q}}_{\perp}}+1\right)-\overline{\mathrm{n}}_{\mathrm{n}, \mathrm{N}, \overrightarrow{\mathrm{k}}_{\perp}} \cdot \mathrm{N}_{\mathrm{m}, \overrightarrow{\mathrm{q}}_{\perp}}}{\varepsilon_{\mathrm{n}, \mathrm{N}}^{\mathrm{H}}\left(\overrightarrow{\mathrm{k}}_{\perp}\right)-\varepsilon_{\mathrm{n}^{\prime}, \mathrm{N}^{\prime}}^{\mathrm{H}}\left(\overrightarrow{\mathrm{k}}_{\perp}-\overrightarrow{\mathrm{q}}_{\perp}\right)+\hbar \omega_{\mathrm{m}, \overrightarrow{\mathrm{q}}_{\perp}}-\mathrm{g} \hbar \Omega+\mathrm{i} \hbar \delta}\right\}
\end{aligned}
$$

where $\overline{\mathrm{n}}_{\mathrm{n}, \mathrm{N}, \overrightarrow{\mathrm{k}}_{\perp}}$ is the time - independent component of the electron distribution fuction; $\mathrm{J}_{\mathrm{g}}(\mathrm{x})$ is the Bessel function. Eq.(8) also can be considerd a general expression of the electron distribution function in two dimensional systems with the electron form factor and the electron energy spectrum of each system.

\subsection{Calculations of the nonlinear absorption coefficient of a strong electromagnetic wave by confined electrons in a quantum well in the presence of a magnetic field with case of confined phonons}

The nonlinear absorption coefficient of a strong electromagnetic wave by confined electrons in the two-dimensional systems takes the simple form (Shmelev, 1978):

$$
\alpha=\frac{8 \pi}{\mathrm{c} \sqrt{\chi_{\infty}} \mathrm{E}_{\mathrm{o}}^{2}}\left\langle\overrightarrow{\mathrm{j}}_{\perp}(\mathrm{t}) \overrightarrow{\mathrm{E}}_{\mathrm{o}} \sin \Omega \mathrm{t}\right\rangle_{\mathrm{t}}
$$

Because the motion of electrons is confined along $\mathrm{z}$ direction in quantum wells, we only consider the in plane $(x, y)$ current density vector of electrons so the carrier current density formula in quantum wells is taken the form(Shmelev, et al., 1978):

$$
\vec{j}_{\perp}(t)=\frac{e \hbar}{m^{*}} \sum_{n, N, \vec{k}_{\perp}}\left(\vec{k}_{\perp}-\frac{e}{\hbar c} \vec{A}(t)\right) n_{n, N, \vec{k}_{\perp}}=-\frac{e^{2} \hbar n_{o}^{*} \vec{E}_{o}}{m^{*} \Omega} \cos (\Omega t)+\frac{e \hbar}{m^{*}} \sum_{n, N, \vec{k}_{\perp}} \vec{k}_{\perp} n_{n, N, \vec{k}_{\perp}}(t)
$$

with $n_{\mathrm{o}}^{*}=\frac{\mathrm{n}_{\mathrm{o}}(\pi \mathrm{e})^{3 / 2}}{\mathrm{~V} \cdot\left(\mathrm{m}_{\mathrm{o}} \mathrm{k}_{\mathrm{B}} \mathrm{T}\right)^{3 / 2}}, \mathrm{n}_{\mathrm{o}}$ is the electron density in quantum well, $\mathrm{m}_{\mathrm{o}}$ is the mass of free electron, $\mathrm{k}_{\mathrm{B}}$ is Boltzmann constant.

By using Eq.(10), the confined electron-confined optical phonon interaction factor $C_{m, \tilde{q}_{\perp}}$ in Eq.(3) and the Bessel function, from the expression of current density vector in Eq.(10) and 
the relation between the nonlinear absorption coefficient of a strong electromagnetic wave with $\overrightarrow{\mathrm{j}}_{\perp}(\mathrm{t})$ in Eq.(9), we established the nonlinear absorption coefficient of a strong electromagnetic wave in a quantum well in the presence of an external magnetic field under influnece of confined phonons:

$$
\begin{gathered}
\alpha=\frac{e^{4} n_{0}^{*} k_{B} T \Omega_{B}^{2} \hbar^{2}}{4 \varepsilon_{0} c \Omega^{3} \pi a_{c}^{2} \sqrt{\chi_{\infty}} \cdot\left(\frac{1}{\chi_{\infty}}-\frac{1}{\chi_{0}}\right) . \sum_{n \neq n^{\prime}, N^{\prime} N^{\prime}} \sum_{m}\left|I_{n, n^{\prime}}^{m}\right|^{2}\left(1+\frac{3 e^{2} E_{0}^{2}}{16 a_{c}^{2} m^{* 2} \Omega^{4}}\left(N+N^{\prime}+1\right)\right) \times} \\
\times\left\{\exp \left[\frac{\left(N+\frac{1}{2}\right) \hbar \Omega_{B}+\frac{\pi^{2} \hbar^{2} n^{2}}{2 m^{* 2} L^{2}}}{k_{B} T}\right]-\exp \left[-\frac{\left(N^{\prime}+\frac{1}{2}\right) \hbar \Omega_{B}+\frac{\pi^{2} \hbar^{2} n^{\prime 2}}{2 m^{* 2} L^{2}}}{k_{B} T}\right]\right\} \times \\
\times \frac{A_{Q}\left|N-N^{\prime}\right|}{\left|N-N^{\prime}\right|\left[\left(N^{\prime}-N\right) \hbar \Omega_{B}+\frac{\pi^{2} \hbar^{2}\left(n^{\prime 2}-n\right)}{2 m^{* 2} L^{2}}+\hbar \omega_{0}-\hbar \Omega+A_{Q} \hbar^{2}\right.}
\end{gathered}
$$

here, $M=N-N^{\prime} ; A_{Q}=N_{o} \frac{\left|C_{o}\right|^{2}}{4 \pi \hbar^{2}} \sum_{n, n^{\prime}}\left|I^{m}{ }_{n, n^{\prime}}\right|^{2} ; \mathrm{N}_{o}=\frac{k_{B} T}{\hbar \omega_{o}} ;\left|C_{o}\right|^{2}=\frac{2 \pi e^{2} \hbar \omega_{o}}{\varepsilon_{o} V}\left(\frac{1}{\chi_{\infty}}-\frac{1}{\chi_{0}}\right)$

In Eq. (11), it's noted that we only consider the absorption close to its threshold because in the rest case (the absorption far away from its threshold) $\alpha$ is very smaller. In the case, the condition $\left|g \Omega-\omega_{0}\right|<<\bar{\varepsilon}$ ( $\bar{\varepsilon}$ is the average energy of electron) must be satisfied (Pavlovich $\&$ Epshtein, 1977). The formula of the nonlinear absorption coefficient contains the quantum number $\mathrm{m}$ characterizing confined phonons. When quantum number $\mathrm{m}$ characterizing confined phonons reaches to zero, the expression of the nonlinear absorption coefficient for the case of absorption in quantum wells without influences of confined phonons can be written as:

$$
\begin{aligned}
\alpha & =\frac{e^{4} n_{o}^{*} k_{B} T \Omega_{B}^{3}}{2 \pi c L \sqrt{\chi_{\infty}} a_{c}^{2} \cdot \varepsilon_{o} \cdot \Omega^{3} \hbar^{2}}\left(\frac{1}{\chi_{\infty}}-\frac{1}{\chi_{o}}\right) \sum_{n, n^{\prime} N, N^{\prime}} \sum_{\text {. }}\left[1+\frac{3 e^{2} E_{o}^{2}}{8 m^{* 2} a_{c}^{2} \Omega^{4}}\right] \times \\
& \times\left\{\exp \left[-\frac{1}{k_{B} T}\left(N+\frac{1}{2}\right) \hbar \Omega_{B}-\frac{\pi^{2} n^{2} \hbar^{2}}{2 m^{*} L^{2}}\right]-\exp \left[-\frac{1}{k_{B} T}\left(N^{\prime}+\frac{1}{2}\right) \hbar \Omega_{B}-\frac{\pi^{2} n^{\prime 2} \hbar^{2}}{2 m^{*} L^{2}}\right]\right\} \times \\
& \times \frac{\hbar \sqrt{A|M|}}{|M|\left(\hbar \Omega-\hbar \omega_{o}+M \hbar \Omega_{B}+\frac{\pi^{2} \hbar^{2}}{2 m^{*} L^{2}}\left(n^{2}-n^{\prime 2}\right)^{2}+\hbar^{2} A\right)}
\end{aligned}
$$

with $A=N_{o} \frac{e^{2} \omega_{o}}{2 \pi \hbar^{2} L}\left(\frac{1}{\chi_{\infty}}-\frac{1}{\chi_{0}}\right)$

In Eqs.(12) we can see that the formula of the nonlinear absorption coefficient easy to come back to the case of linear absorption when the intensity $\left(E_{0}\right)$ of external electromagnetic wave reaches to zero which was calculated Kubo - Mori method (Bau \& Phong, 1998). 


\subsection{Numerical results and discussion}

In order to clarify the mechanism for the nonlinear absorption coefficient of a strong electromagnetic wave in a quantum well with case of confined, in this section, we will evaluate, plot and discuss the expression of the nonlinear absorption coefficient for a specific quantum well: AlAs/GaAs/AlAs. We use some results for linear absorption in (Bau\&Phong, 1998) to make the comparison. The parameters used in the calculations are as follows (Pavlovich, 1978): $\varepsilon_{0}=12.5 ; \quad \chi_{0}=12.9, \quad \chi_{\infty}=10.9, \quad n_{o}=10^{23} \mathrm{~m}^{-3}, \quad L=100 A^{0}$, $\mathrm{m}^{*}=0.067 \mathrm{~m}_{\mathrm{o}}, \mathrm{m}_{\mathrm{o}}=9.1 .10^{-31} \mathrm{Kg}, \mathrm{k}_{\mathrm{B}}=1.3807 \times 10^{-23}, \Omega=2.10^{14} \mathrm{~s}^{-1}, \hbar \omega_{m, \vec{q}_{\perp}} \approx \hbar \omega_{o}=36.25 \mathrm{meV}$.

Fig. (1-2) show the nonlinear and the linear absorption coeffcients in quantum wells in the presence of an external magnetic field for the case of confined electron - optical phonon scattering. The dependence of the absorption coeffcient on the frequency $\Omega$ of an external, strong electromagnetic wave and on the cyclotron frequency $\Omega_{\mathrm{B}}$ for the case of an external magnetic field has one main maximum and several neighboring secondary maxima. The further away from the main maximum, the secondary one is the smaller. But in case of absence of an external magnetic field, there are only two maxima of nonlinear absorption coeffcient (Bau et al., 2010). When we consider case $E_{o}=0$ and $\mathrm{m}$ reaches to zero, the nonlinear result with case confined phonon, will turn back to the linear result with case of unconfined phonons which was calculated by using another method the Kubo - Mori method (Bau\&Phong, 1998).

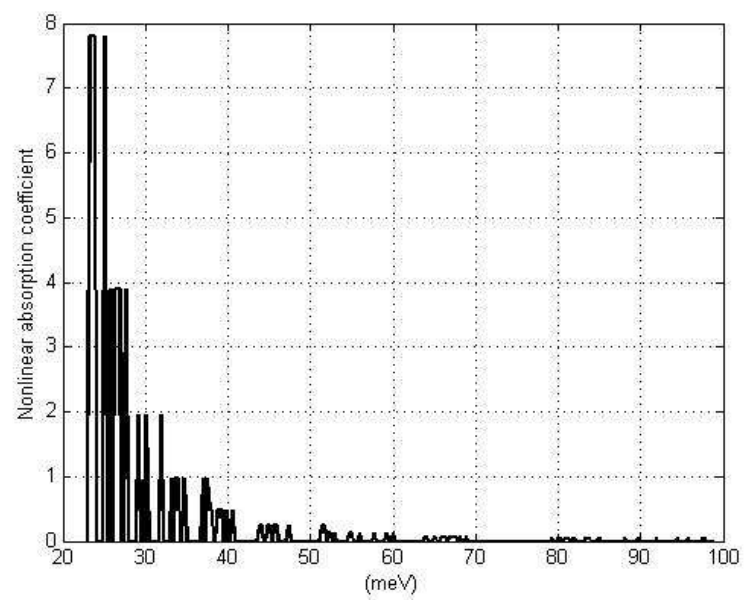

Fig. 1. The dependence of nonlinear absorption coefficient on $\hbar \Omega$ in case of confined phonons

Another point is that the absorption coeffcient in the presence of an external magnetic field is smaller than that without a field (Bau et al., 2010) because in this case, the number of electrons joining in the absorption process is limited. In addition, the Landau level that electrons can reach must be defined. In other word, the index of the Landau level that an electron can reach to after the absorption process must satisfy the condition:

$$
\left(n^{\prime 2}-n^{2}\right) \frac{\pi^{2} \hbar^{2}}{2 m^{*} L^{2}}+M \hbar \Omega_{B}-\hbar \omega_{o}+\hbar \Omega=0
$$


This is different from that for normal bulk semiconductors (index of the Landau level that electrons can reach after the absorption process is arbitrary), therefore, the dependence of the absorption coeffcient on $\Omega_{\mathrm{B}}$ and $\Omega$ is not continuous.
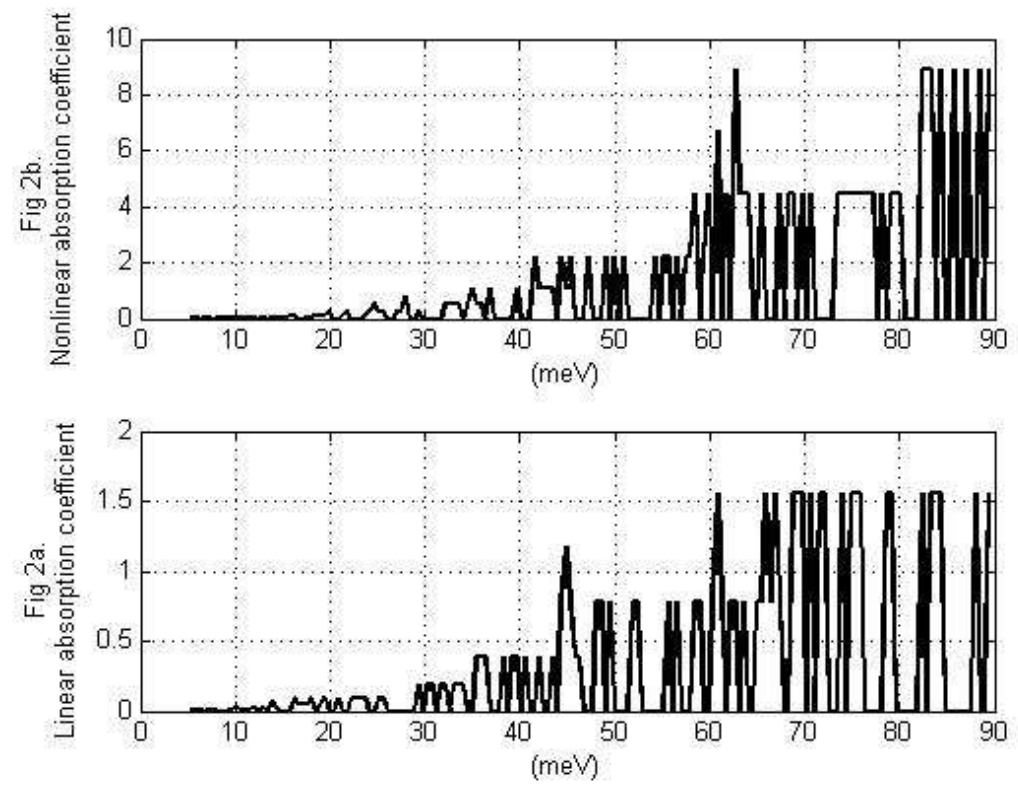

Fig. 2. The dependence of absorption coefficient on $\hbar \Omega_{B}$ in case of confined phonons

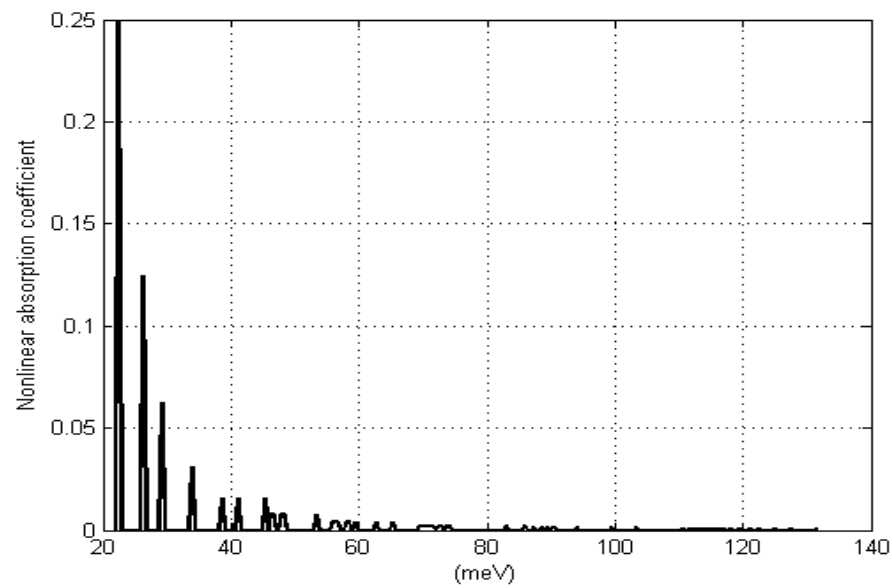

Fig. 3. The dependence of nonlinear absorption coefficient on $\hbar \Omega$ in case of unconfined phonons 

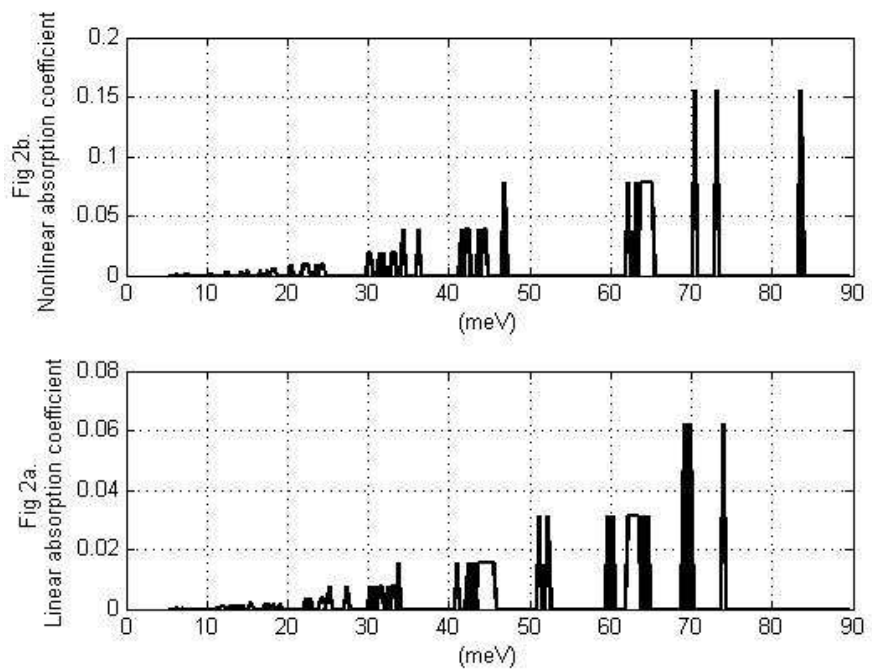

Fig. 4. The dependence of absorption coefficient on $\hbar \Omega_{B}$ in case of unconfined phonons
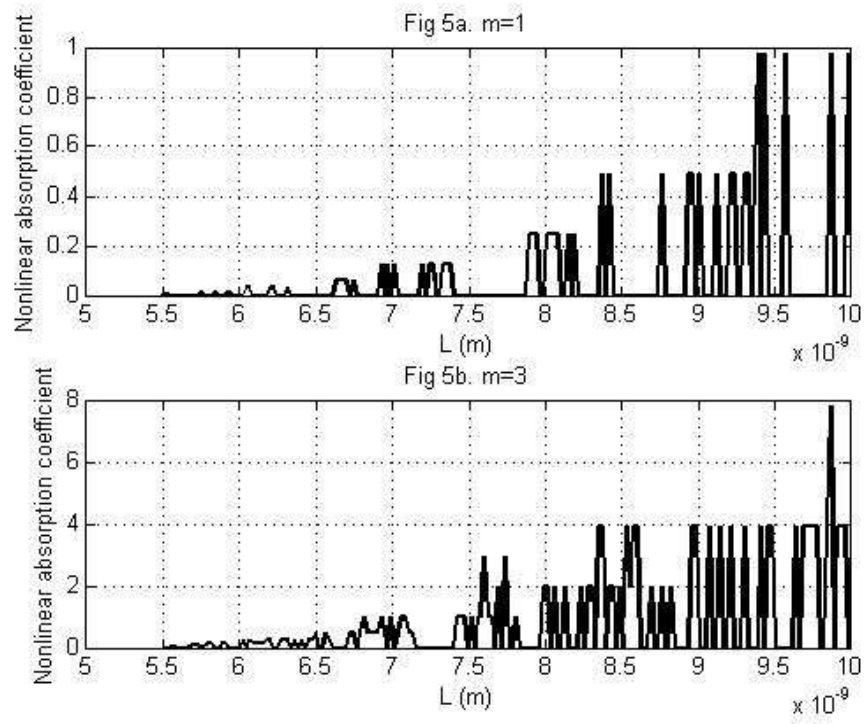

Fig. 5. The dependence of nonlinear absorption coefficient on $\mathrm{L}$ in case of confined phonons $(\mathrm{m}=1, \mathrm{~m}=3)$

Fig. (3-4) show the nonlinear and the linear absorption coeffcients in quantum wells in the presence of an external magnetic field for the case of unconfined phonons (Bau et al., 2009). All figs show that the confinement of optical phonons have effected much strongly on absorption coeffcients. There is difference in the spectrum of absorption coeffcients in case confined phonons from its in case unconfined phonons. In fig.(1), the density of 
resonancepeaks is greater and the value of absorption coeffcients is higher than its with case unconfined phonons (fig.3) in both of the nonlinear and the linear absorption. In fig.4, some of resonance peaks have changed these position. These points are quite similar to case of confined phonons with out influence of an external magnetic field (Bau et al., 2010).

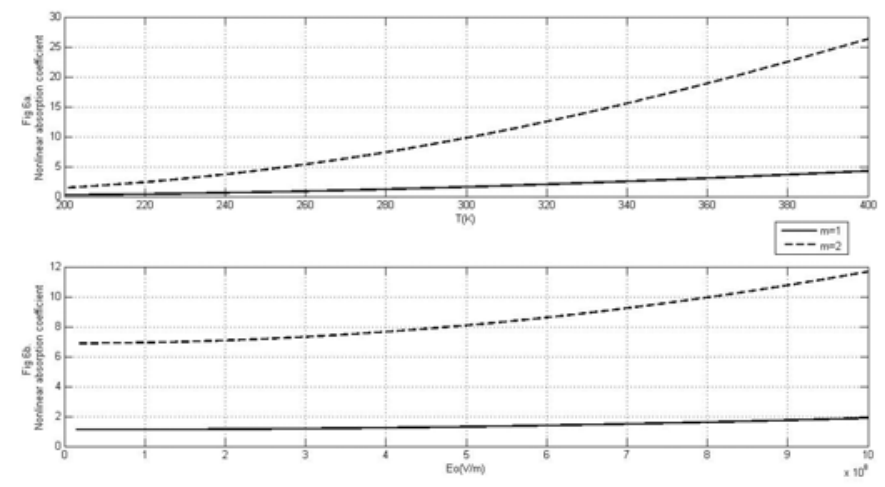

Fig. 6. The dependence of nonlinear absorption coefficient on $\mathrm{T}$ and $\mathrm{E}_{\mathrm{o}}$ in case of confined phonons $(\mathrm{m}=1, \mathrm{~m}=2)$

In fig.5, the dependence of the nonlinear absorption coeffcient on the quantum well's width has several maxima while each curve has one maximum peak in absence of a magnetic field (Bau et al., 2010). Fig.6 shows the dependence of the nonlinear absorption coeffcient on $\mathrm{T}$ and $E_{0}$. Both of fig. $(5,6)$ show that the absorption coeffcient depends much strongly on quantum number $\mathrm{m}$ characterizing confined phonons, it gets greater when $\mathrm{m}$ increases.

\section{Effect of magnetic field on nonlinear absorption of a strong electromagnetic wave in a doped superlattice}

\subsection{Calculations of the nonlinear absorption coefficient of a strong electromagnetic wave by confined electrons in a doped superlattice in the presence of a magnetic field with case of confined phonons}

In doped superlattices, in the presence of an external magnetic field, the confined electron energy takes the simple form:

$$
\left.\left.\varepsilon_{n, N}^{H}\left(\vec{k}_{\perp}\right)=\hbar \omega_{p} \square_{\square} n+\frac{1}{2}\right\rceil+\hbar \Omega_{B} \square_{\square} N+\frac{1}{2}\right\rceil
$$

with, $\omega_{p}=\left(\frac{4 \pi e^{2} n_{D}}{\varepsilon_{o} m^{*}}\right)^{1 / 2}$ is the frequency plasma caused by donor doping concentration, $n_{D}$ is the doping concentration. The electron form factor $I^{m}{ }_{n, n^{\prime}}$ can be written as:

$$
I_{n, n^{\prime}}^{m}=\sum_{m}^{N_{1}} \int_{0}^{d} \phi_{n^{\prime}}(z-m d) e^{i q_{z} m d} \phi_{n}(z-m d) d z
$$


Here $\phi_{n}(z)$ is the eigenfunction for a single potential which compose the doped superlattices potential, $\mathrm{d}$ is the doped superlattices period, $\mathrm{N}_{1}$ is the number of doped superlattices period.

The electron distribution function in doped superlattices can be written as Eq.(8) with the electron energy spectrum and the electron form factor in Eq. (13) and Eq.(14). We insert the expression for $n_{n, N, \vec{k}_{\perp}}(t)$ for a doped superlattice into the expression for $\vec{j}_{\perp}(t)$ and then insert the expression for $\overrightarrow{\mathrm{j}}_{\perp}(\mathrm{t})$ into the expression for $\alpha$ in Eq.(9). Using the properties of Bessel function and realizing the calculations, the time - independent component of the electron distribution function and the confined electron-confined optical phonon interaction constants, we can calculate to obtain expression of the carrier current density and the nonlinear absorption coefficient of a strong electromagnetic wave by confined electrons in a doped superlattice. We obtain the explicit expression of $\alpha$ in a doped superlattice for the case electron-optical phonon scattering:

$$
\begin{gathered}
\alpha=\frac{e^{4} n_{o}^{*} k_{B} T \Omega_{B}}{4 \pi e_{o} m^{*} c \sqrt{x_{\infty}} a_{c}^{2} \Omega^{3}}\left(\frac{1}{\chi_{\infty}}-\frac{1}{\chi_{\infty}}\right) \sum_{n, n^{\prime}, N, N^{\prime}}\left|I^{m}{ }_{n, n^{\prime}}\right|^{2}\left[1+\left(N+N^{\prime}+1\right) \frac{3 e^{2} E_{o}^{2}}{16 m^{*^{2}} a_{c}^{2} \Omega^{4}}\right] \times n \sqrt{A_{D S L}\left|N-N^{\prime}\right|} \\
\times \frac{\left\{\exp \left[-\frac{1}{k_{B} T}\left(\hbar \omega_{p}\left(n+\frac{1}{2}\right)+\hbar \Omega_{B}\left(N+\frac{1}{2}\right)\right]-\exp \left[-\frac{1}{k_{B} T}\left(\hbar \Omega_{B}\left(N^{\prime}+\frac{1}{2}\right)+\hbar \omega_{p}\left(n^{\prime}+\frac{1}{2}\right)\right)\right]\right\}\right.}{\mid N-N^{\prime}\left[\left[n\left(\Omega-\omega_{o}\right)+n \Omega_{B}\left(N-N^{\prime}\right)+n \omega_{p}\left(n-n^{\prime}\right)\right]^{2}+\hbar^{2} A_{D S L}\right.}
\end{gathered}
$$

Here,

$$
A_{D S L}=N_{o} \frac{\left|C_{o}\right|^{2}}{4 \pi \hbar^{2}} \sum_{m, n, n^{\prime}}\left|I^{m}{ }_{n, n^{\prime}}\right|^{2} ;
$$

In Eq. (15), it's noted that we only consider the absorption close to its threshold. In the case, the condition $\left|\mathrm{g} \Omega-\omega_{\mathrm{o}}\right|<<\bar{\varepsilon}$ must be satisfied (Pavlovich \& Epshtein, 1977). The formula of the nonlinear absorption coefficient contains the quantum number $\mathrm{m}$ characterizing confined phonons. When quantum number $\mathrm{m}$ characterizing confined phonons reaches to zero, the expression of the nonlinear absorption coefficient for the case of absorption close its threshold in a doped superlattice in case of unconfined phonons can be written as:

$$
\begin{gathered}
\alpha=\frac{e^{4} n_{o}^{*} k_{B} T \Omega_{B}}{4 \pi e_{0} m^{*} c \sqrt{x_{\infty}} a_{c}^{2} \Omega^{3}}\left(\frac{1}{\chi_{\infty}}-\frac{1}{\chi_{\infty}}\right) \sum_{n, n^{\prime}, N, N^{\prime}}\left|I^{m}{ }_{n, n^{\prime}}\right|^{2}\left[1+\left(N+N^{\prime}+1\right) \frac{3 e^{2} E_{o}^{2}}{16 m^{* 2} a_{c}^{2} \Omega^{4}}\right] \\
\times \frac{\left\{\exp \left[-\frac{1}{k_{B} T}\left(\hbar \omega_{p}\left(n+\frac{1}{2}\right)+\hbar \Omega_{B}\left(N+\frac{1}{2}\right)\right)\right]-\exp \left[-\frac{1}{k_{B} T}\left(\hbar \Omega_{B}\left(N^{\prime}+\frac{1}{2}\right)+\hbar \omega_{p}\left(n^{\prime}+\frac{1}{2}\right)\right)\right]\right\}}{\left|N-N^{\prime}\right|\left[n\left(\Omega-\omega_{0}\right)+n \Omega_{B}\left(N-N^{\prime}\right)+n \omega_{p}\left(n-n^{\prime}\right)\right]^{2}+\hbar^{2} A^{*}} \\
\times \frac{1}{\pi} e^{-2\left(\frac{N_{1} d}{a_{1}}\right)^{2}}\left(\frac{N_{1} d}{a_{1}}\right)^{2}\left[1+\frac{2}{3}\left(\frac{N_{1} d}{a_{1}}\right)^{2}\right]^{2} n \sqrt{A^{*}\left|N-N^{\prime}\right|}
\end{gathered}
$$

Here, 


$$
\begin{gathered}
A^{*}=\left.\frac{N_{0} e^{2} \omega_{0}}{2 \hbar}\left\lceil\frac{1}{\chi_{\square}}-\frac{1}{\chi_{0}}\right) e^{-\left.2 \frac{N_{1} d}{a_{1}}\right|^{2}} \square \frac{N_{1} d}{a_{1}}\right|^{2}\left\lceil 1+\frac{2}{3}\left\lceil\left.\left.\frac{N_{1} d}{a_{1}}\right|^{2 \bigsqcup^{2}}\right|^{\square}\right.\right. \\
a_{1}=\frac{\hbar}{m^{*} \omega_{p}} ;
\end{gathered}
$$

The term in proportion to quadratic intensity of a strong electromagnetic wave tend toward zero, the nonlinear result in Eqs.(16), will turn back to the linear case which was calculated by another method the Kubo - Mori (Bau et al., 2002).

\subsection{Numerical results and discussion}

In order to clarify the mechanism for the nonlinear absorption of a strong electromagnetic wave in a doped superlattices, in this section, we will evaluate, plot and discuss the expression of the nonlinear absorption coefficient for the case of a specific doped superlattices n-GaAs/p-GaAs. We use some results for nonlinear absorption in case absence of external magnetic field (Bau et al., 2010) to make the comparison. The parameters used in the calculations are as follows: $\chi_{\infty}=10,9 ; \chi_{o}=12,9 ; \mathrm{n}_{\mathrm{o}}=10^{23} \mathrm{~m}^{-3} ; \varepsilon_{0}=12.5 ; \mathrm{m}^{*}=0,067 \mathrm{~m}_{\mathrm{o}}, \mathrm{d}=$ $800 \mathrm{~A}^{0}$ being the doped superlattices period, $\hbar \omega_{m, \vec{q}_{\perp}} \approx \hbar \omega_{o}=36.25 \mathrm{meV} ; \quad \Omega=5.5 .1013 \mathrm{~s}^{-1}, \mathrm{~T}=$ $300 \mathrm{~K}, \mathrm{e}=2.07 \mathrm{e}_{0}, \mathrm{e}_{\mathrm{o}}=1.6 \cdot 10^{-19} \mathrm{C}$.

Fig.7 and fig.8 show the dependence of nonlinear absorption coefficient $\alpha$ in doped superlattices on the intensity, $E_{0}$, of the electromagnetic wave is strong for the two cases present and absent magnetic field. Graph shows, the absorption coefficient dependency strong and nonlinear on the intensity $E_{o}$ of electromagnetic waves. When the intensity of $E_{o}$ increases, the absorption coefficient also increased rapidly. However, for the case present external magnetic field, the value of the nonlinear coefficient absorption larger than when absent external magnetic field.

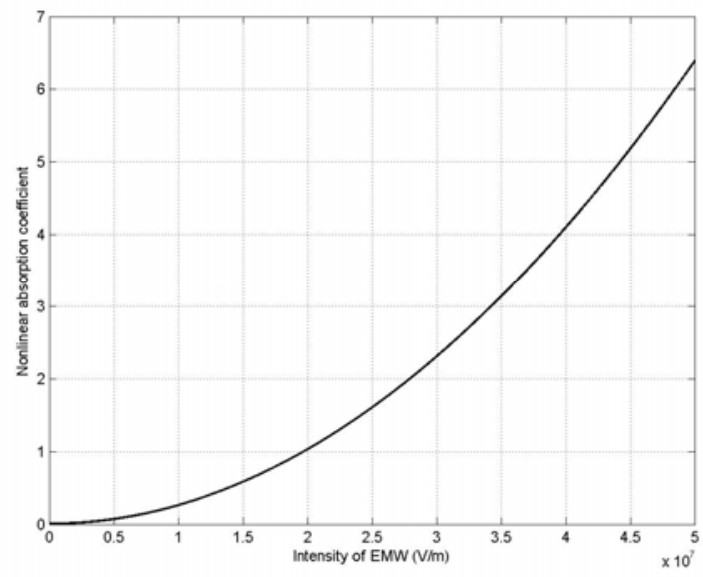

Fig. 7. The dependence of $\alpha$ on the $\mathrm{E}_{\mathrm{o}}$ (Absence of an external magnetic field) 


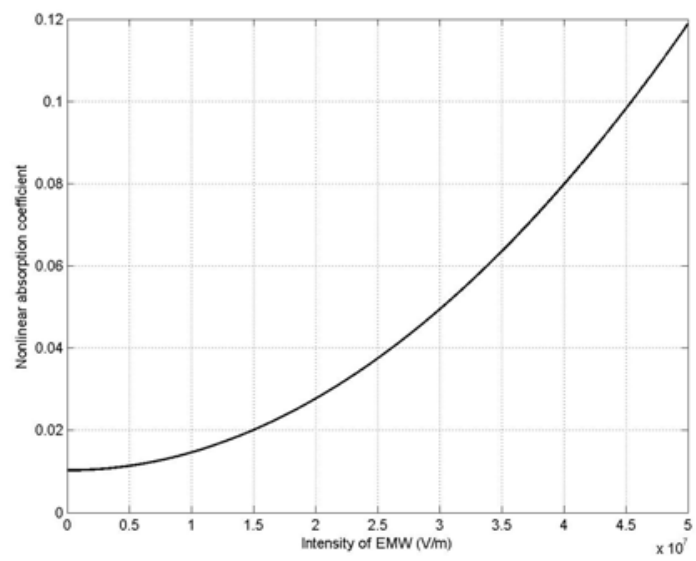

Fig. 8. The dependence of $\alpha$ on the $\mathrm{E}_{\mathrm{o}}$ (Presence of an external magnetic field)

Fig.9 and fig.10 are the results from the survey of absorption coefficient on temperature and concentration of concentration doped. Graph shows absorption coefficient is also dependence strong and nonlinear on temperature $\mathrm{T}$ and concentration doped $n_{D}$. For both cases present and absent magnetic field, nonlinear absorption coefficient increased, when the temperature and the concentration doped of the system increases. Causes of this phenomenon: when the temperature and the concentration doped of system increases, leading to increased particle density, increased stimulation resulting vibrations in the material particles so that absorption coefficient of electromagnetic waves increased.

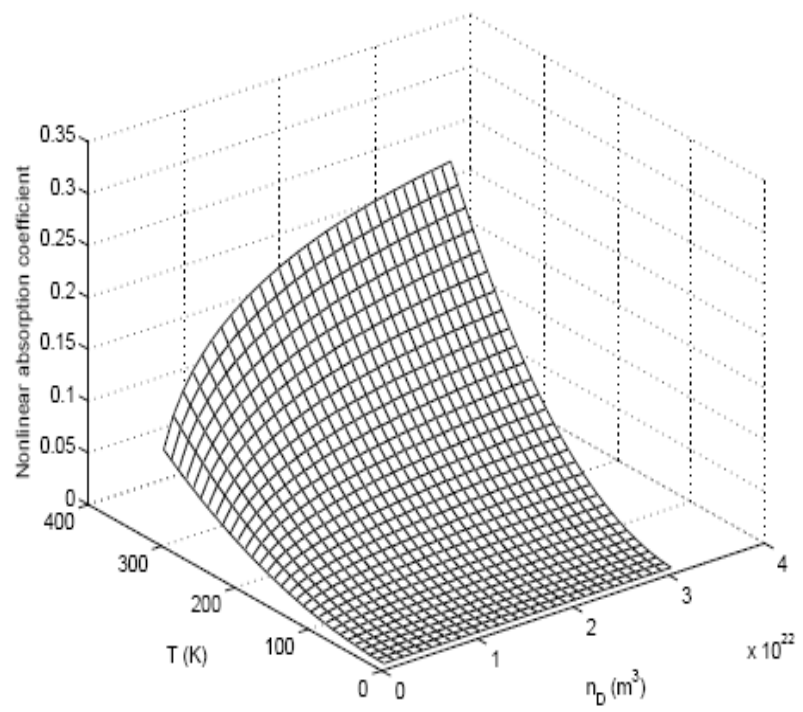

Fig. 9. The dependence of $\alpha$ on the $n_{D}$ and T (Absence of an external magnetic field) 


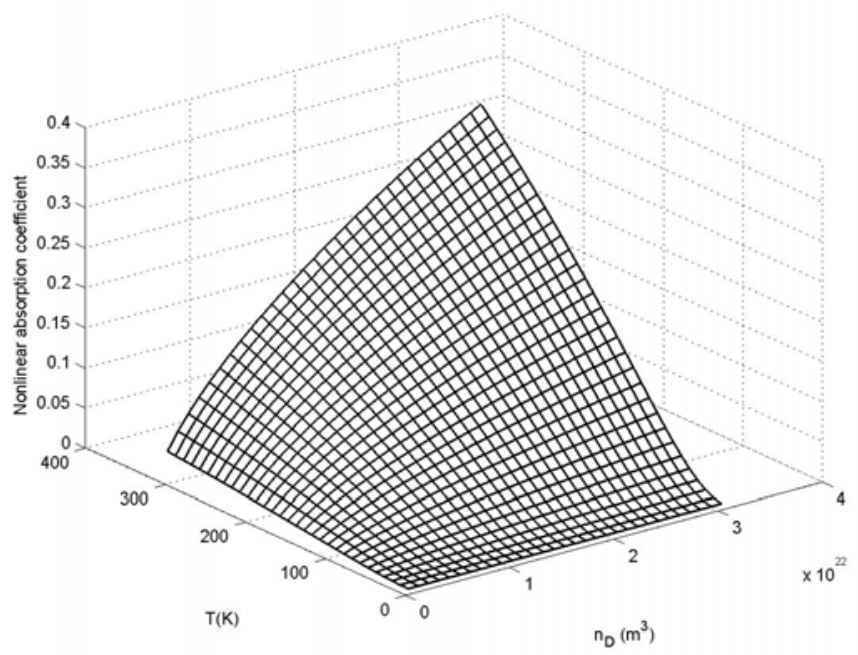

Fig. 10. The dependence of $\alpha$ on the $n_{D}$ and T (Presence of an external magnetic field)

Fig.11 and fig. 12 show the dependence of the nonlinear absorption coefficient $\alpha$ on the energy $\hbar \Omega$ in doped superlattices of an external strong electromagnetic wave for the cases two absent and present magnetic field. Graphs show clearly the difference between them.

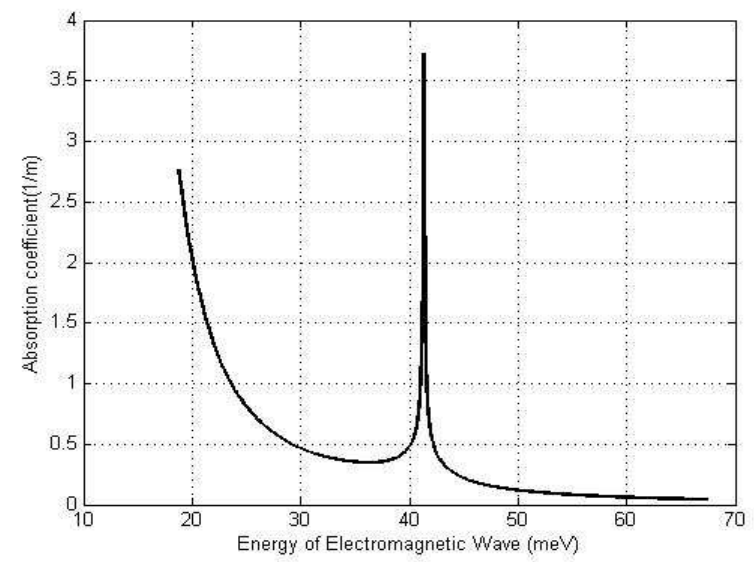

Fig. 11. The dependence of $\alpha$ on the $\hbar \Omega$ (Absence of an external magnetic field)

In fig.11, energy absorption spectrum have one resonance peak in case absence of magnetic field, but in fig.12, energy absorption spectrum is interrupted in the case presence of magnetic field. The absorption coefficient strong increases more in the case absence of magnetic field. The line spectrum formation of absorption coefficient in fig. 12 clearly shows the influence of magnetic field on the absorption coefficient of strong external 
electromagnetic waves. This difference can be explained: in the presence of a magnetic field, the energy spectrum of electronic is interruptions. In addition, the Landau level that electrons can reach must be defined. In other word, the index of the absorption process must satisfy the condition:

$$
\hbar \omega_{p}\left(n^{\prime}-n\right)+\hbar \Omega_{B}\left(N^{\prime}-N\right)+\hbar \omega_{o}-\hbar \Omega=0
$$

in function Delta - Dirac. This is different from that for case absent a magnetic field (index of the landau level that electrons can reach after the absorption process is arbitrary), therefore, the dependence of the absorption coefficient $\alpha$ on $\hbar \Omega$ is not continuous.

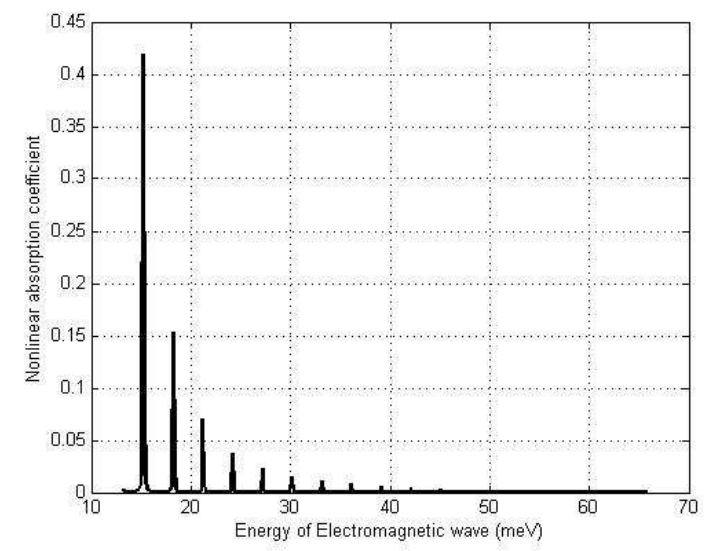

Fig. 12. The dependence of $\alpha$ on the $\hbar \Omega$ (Presence of an external magnetic field)

\section{Effect of magnetic field on nonlinear absorption of a strong electromagnetic wave in a cylindrical quantum wire}

4.1 The electron distribution function in a cylindrical quantum wire in the presence of a magnetic field with case of confined phonons

We consider a wire of GaAs with a circular cross section with radius $R$ and length $L_{z}$ embedded in AlAs. The carries (confined electrons) are assumed to be confined by infinite potential barriers and free along the wire's axis $(\mathrm{Oz})$. A constant magnetic field with the magnitude $\vec{B}$ is applied parallel to the axis of wire. In the case, the Hamiltonian is given by (Bau \& Trien, 2010):

$$
\begin{aligned}
& \mathrm{H}=\sum_{\mathrm{n}, \ell, \mathrm{N}, \overrightarrow{\mathrm{k}}_{\mathrm{z}}} \varepsilon_{\mathrm{n}, \ell, \mathrm{N}}\left(\overrightarrow{\mathrm{k}}_{\mathrm{z}}-\frac{\mathrm{e}}{\hbar \mathrm{c}} \overrightarrow{\mathrm{A}}(\mathrm{t})\right) \cdot \mathrm{a}_{\mathrm{n}, \ell, \mathrm{N}, \overrightarrow{\mathrm{k}}_{\mathrm{z}}}^{+} \mathrm{a}_{\mathrm{n}, \ell, \mathrm{N}, \overrightarrow{\mathrm{k}}_{\mathrm{z}}}+\sum_{\mathrm{m}, \mathrm{k}, \overrightarrow{\mathrm{q}}_{\mathrm{z}}} \hbar \omega_{\mathrm{m}, \mathrm{k}, \overrightarrow{\mathrm{q}}_{\mathrm{z}}} \cdot \mathrm{b}_{\mathrm{m}, \mathrm{k}, \overrightarrow{\mathrm{q}}_{\mathrm{z}}}^{+} \cdot \mathrm{b}_{\mathrm{m}, \mathrm{k}, \overrightarrow{\mathrm{q}}_{\mathrm{z}}}+ \\
& \sum_{\substack{\mathrm{n}^{\prime}, \ell^{\prime}, \mathrm{N}, \overrightarrow{\mathrm{z}}_{\mathrm{z}} \\
\mathrm{n}, \ell, \mathrm{N}_{\mathrm{z}}, \mathrm{q}_{\mathrm{z}}}} \sum_{\mathrm{m}, \mathrm{k}} \mathrm{C}_{\overrightarrow{\mathrm{q}}_{\mathrm{z}}}^{\mathrm{m}, \mathrm{k}} \mathrm{I}_{\mathrm{n} \ell, \mathrm{n}^{\prime} \ell}^{\mathrm{m}, \mathrm{k}} \mathrm{J}_{\mathrm{N}, \mathrm{N}^{\prime}}(\mathrm{u}) \mathrm{a}_{\mathrm{n}^{\prime}, \ell^{\prime}, \mathrm{N}^{\prime}, \overrightarrow{\mathrm{k}}_{\mathrm{z}}+\overrightarrow{\mathrm{q}}_{\mathrm{z}}}^{+} \mathrm{a}_{\mathrm{n}, \ell, \mathrm{N}, \overrightarrow{\mathrm{k}}_{\mathrm{z}}}\left(\mathrm{b}_{\mathrm{m}, \mathrm{k}, \overrightarrow{\mathrm{q}}_{\mathrm{z}}}+\mathrm{b}_{\mathrm{m}, \mathrm{k}, \overrightarrow{\mathrm{q}}_{\mathrm{z}}}^{+}\right)
\end{aligned}
$$

Where the sets of quantum numbers $(n, \ell, N)$ and $\left(n^{\prime}, \ell^{\prime}, N^{\prime}\right)$, characterizing the states of electron in the quantum wire before and after scattering with phonon; $a_{n, \ell, N, \vec{k}_{\mathrm{z}}}^{+}\left(a_{n, \ell, N, \vec{k}_{\mathrm{z}}}\right)$ is the 
creation (annihilation) operator of a confined electron; $\overrightarrow{\mathrm{k}}_{\mathrm{z}}$ is the electron wave vector (along the wire's $\mathrm{z}$ axis); $\mathrm{b}_{\mathrm{m}, \mathrm{k}, \mathrm{q}_{\mathrm{z}}}^{+}\left(\mathrm{b}_{\mathrm{m}, \mathrm{k}, \mathrm{q}_{\mathrm{z}}}\right)$ is the creation operator (annihilation operator) of a confined optical phonon for state have wave vector $\overrightarrow{\mathrm{q}}_{\mathrm{z}} ; \omega_{\mathrm{m}, \mathrm{k}, \mathrm{q}_{\mathrm{z}}}$ is the frequency of confined optical phonon, which was written as (Yu et al., 2005; Wang et al., 1994): $\omega_{\mathrm{m}, \mathrm{k}, \mathrm{q}}^{2}=\omega_{0}^{2}-\beta^{2}\left(\mathrm{q}_{\mathrm{z}}^{2}+\mathrm{q}_{\mathrm{m}, \mathrm{k}}^{2}\right)$, with $\beta$ is the velocity in cylindrical quantum wire and $\omega_{0}$ is the frequency of optical phonon; $(\mathrm{m}, \mathrm{k})$ are quantum numbers characterizing confined phonons; the electron form factor $\mathrm{I}_{\mathrm{n} \ell, \mathrm{n}^{\prime} \ell^{\prime}}^{\mathrm{m}, \mathrm{k}}$ can be written from (Li et al., 1992):

$$
\mathrm{I}_{\mathrm{n} \ell, \mathrm{n}^{\prime} \ell^{\prime}}^{\mathrm{m}, \mathrm{f}}\left(\mathrm{q}_{\mathrm{m}, \mathrm{k}}\right)=\frac{2}{\mathrm{R}^{2}} \int_{0}^{\mathrm{R}} \mathrm{J}_{\left|\mathrm{n}-\mathrm{n}^{\prime}\right|}\left(\mathrm{q}_{\mathrm{m}, \mathrm{k}} \mathrm{R}\right) \cdot \psi_{\mathrm{n}^{\prime}, \ell^{\prime}}^{*}(\mathrm{r}) \cdot \psi_{\mathrm{n}, \ell}(\mathrm{r}) \cdot \mathrm{rdr}
$$

The electron-optical phonon interaction constants can be taken as:

$$
\left|\mathrm{C}_{\mathrm{q}_{z}, \mathrm{k}}^{\mathrm{m}}\right|^{2}=\pi \mathrm{e}^{2} \hbar \omega_{\mathrm{o}} \cdot\left(1 / \chi_{\infty}-1 / \chi_{\mathrm{o}}\right) / 2 \mathrm{~V} \varepsilon_{\mathrm{o}}\left(\mathrm{q}_{\mathrm{z}}^{2}+\mathrm{q}_{\mathrm{m}, \mathrm{k}}^{2}\right)
$$

Here $V$ is the normalization volume, $\varepsilon_{0}$ is the permittivity of free space, $\chi_{\infty}$ and $\chi_{0}$ are the high and low-frequency dielectric constants, $\mathrm{q}_{\mathrm{m}, \mathrm{k}}^{2}$ can be written from (Yu et al., 2005; Wang et al., 1994):

$$
q_{m, k}=\left\{\begin{array}{l}
x_{k}^{1} / R \text { when } \mathrm{m}=0 \\
\mathrm{~h}_{\mathrm{k}}^{\mathrm{m}} / R \text { when }|\mathrm{m}|=2 \mathrm{~s}+1 ; \mathrm{s}=0,1,2 \ldots, \\
\mathrm{g}_{\mathrm{k}}^{\mathrm{m}} / R \text { when }|\mathrm{m}|=2 \mathrm{~s} ; \mathrm{s}=1,2,3 \ldots
\end{array},\right.
$$

and $\mathrm{J}_{\mathrm{N}, \mathrm{N}^{\prime}}(\mathrm{u})$ takes the form (Suzuki et al., 1992; Generazio et .al, 1979; Ryu et al., 1993; Chaubey et al., 1986):

$$
J_{N, N^{\prime}}(u)=\int_{-\infty}^{+\infty} d r \phi_{N^{\prime}}\left(\vec{r}_{z}-a_{c}^{2}\left(\vec{k}_{z}-\vec{q}_{z}\right)\right) \cdot e^{i \vec{q}_{z} \cdot \vec{k}_{z}} \phi_{N}\left(\vec{r}_{z}-a_{c}^{2} \vec{k}_{z}\right)
$$

Here $\phi_{\mathrm{N}}(\mathrm{x})$ represents the harmonic wave function.

When the magnetic field is strong and the radius $R$ of wires is very bigger than cyclotron radius $\mathrm{a}_{\mathrm{c}}$, the electron energy spectra have the form:

$$
\varepsilon_{\mathrm{n}, \ell, \mathrm{N}, \overrightarrow{\mathrm{k}}_{\mathrm{z}}}=\frac{\hbar^{2} \mathrm{k}_{\mathrm{z}}^{2}}{2 \mathrm{~m}^{*}}+\hbar \Omega_{\mathrm{B}}\left(\mathrm{N}+\frac{\mathrm{n}}{2}+\frac{\ell}{2}+\frac{1}{2}\right) \text { with } \mathrm{N}=0,1,2, \ldots,
$$

In order to establish analytical expressions for the nonlinear absorption coefficient of a strong electromagnetic wave by confined electrons in cylindrical quantum wire, we use the quantum kinetic equation for particle number operator of electron $\mathrm{n}_{\mathrm{n}, \ell, \mathrm{N}, \overrightarrow{\mathrm{k}}_{\mathrm{z}}}(\mathrm{t})=\left\langle\mathrm{a}_{\mathrm{n}, \ell, \mathrm{N}, \overrightarrow{\mathrm{k}}_{\mathrm{z}}^{+}}^{+} \mathrm{a}_{\mathrm{n}, \ell, \mathrm{N}, \overrightarrow{\mathrm{k}}_{\mathrm{z}}}\right\rangle_{\mathrm{t}}$ :

$$
\frac{i \partial_{n_{n, \ell, N, \bar{k}_{z}}(t)}}{\partial t}=\left\langle\left[a_{n, \ell, N, \vec{k}_{z}}^{+} a_{n, \ell, N, \vec{k}_{z}}, H\right]\right\rangle_{t}
$$

Where $\langle\psi\rangle_{t}$ is the statistical average value at the moment $\mathrm{t}$ and $\langle\psi\rangle_{t}=\operatorname{Tr}(\hat{W} \hat{\psi})(\hat{W}$ being the density matrix operator). Starting from the Hamiltonian Eq. (18) and using the 
commutative relations of the creation and the annihilation operators, we obtain the quantum kinetic equation for electrons in cylindrical quantum wire in the presence of a magnetic field with case of confined phonons:

$$
\begin{aligned}
& \frac{\partial \mathrm{n}_{\gamma, \overrightarrow{\mathrm{k}}_{\mathrm{z}}}(\mathrm{t})}{\partial \mathrm{t}}=-\sum_{\gamma^{\prime}, \overrightarrow{\mathrm{q}}_{\mathrm{z}}} \sum_{\lambda}\left|\mathrm{C}_{\overrightarrow{\mathrm{q}}_{\mathrm{z}}}^{\lambda}\right|^{2} \cdot\left|\mathrm{I}_{\mathrm{n} \ell, \mathrm{n}^{\prime} \ell^{\prime}}^{\lambda}\right|^{2} \cdot\left|\mathrm{J}_{\mathrm{N}, \mathrm{N}^{\prime}}\right|^{2} \cdot \sum_{\mathrm{g}, \mathrm{s}=-\infty}^{+\infty} \mathrm{J}_{\mathrm{g}}\left(\frac{\mathrm{e} \overrightarrow{\mathrm{E}}_{0} \overrightarrow{\mathrm{q}}}{\mathrm{m}^{*} \Omega^{2}}\right) \cdot \mathrm{J}_{\mathrm{s}}\left(\frac{\mathrm{e} \overrightarrow{\mathrm{E}}_{0} \overrightarrow{\mathrm{q}}}{\mathrm{m}^{*} \Omega^{2}}\right) \cdot \exp [\mathrm{i}(\mathrm{g}-\mathrm{s}) \Omega \mathrm{t}] \int_{-\infty}^{\mathrm{t}} d \mathrm{t}^{\prime} \times \\
& \times\left\{\left[\mathrm{n}_{\gamma, \overrightarrow{\mathrm{k}}_{\mathrm{z}}}\left(\mathrm{t}^{\prime}\right) \cdot\left(\mathrm{N}_{\lambda, \overrightarrow{\mathrm{q}}_{\mathrm{z}}}+1\right)-\mathrm{n}_{\gamma^{\prime}, \overrightarrow{\mathrm{k}}_{\mathrm{z}}+\overrightarrow{\mathrm{q}}_{\mathrm{z}}}\left(\mathrm{t}^{\prime}\right) \cdot \mathrm{N}_{\lambda, \overrightarrow{\mathrm{q}}_{\mathrm{z}}}\right] \times\right. \\
& \times \exp \left\{\mathrm{i}\left(\varepsilon_{\gamma^{\prime}}^{\mathrm{H}}\left(\overrightarrow{\mathrm{k}}_{\mathrm{z}}+\overrightarrow{\mathrm{q}}_{\mathrm{z}}\right)-\varepsilon_{\gamma}^{\mathrm{H}}\left(\overrightarrow{\mathrm{k}}_{\mathrm{z}}\right)+\hbar \omega_{\lambda, \overrightarrow{\mathrm{k}}_{\mathrm{z}}}-\mathrm{g} \hbar \Omega+\mathrm{i} \hbar \delta\right)\left(\mathrm{t}-\mathrm{t}^{\prime}\right)\right\}+ \\
& +\left[\mathrm{n}_{\gamma, \overrightarrow{\mathrm{k}}_{\mathrm{z}}}\left(\mathrm{t}^{\prime}\right) \cdot \mathrm{N}_{\lambda, \overrightarrow{\mathrm{q}}_{\mathrm{z}}}-\mathrm{n}_{\gamma^{\prime}, \overrightarrow{\mathrm{k}}_{\mathrm{z}}+\overrightarrow{\mathrm{q}}_{\mathrm{z}}}\left(\mathrm{t}^{\prime}\right) \cdot\left(\mathrm{N}_{\lambda, \overrightarrow{\mathrm{q}}_{\mathrm{z}}}+1\right)\right] \times \\
& \times \exp \left\{\mathrm{i}\left(\varepsilon_{\gamma^{\prime}}^{\mathrm{H}}\left(\overrightarrow{\mathrm{k}}_{\mathrm{z}}+\overrightarrow{\mathrm{q}}_{\mathrm{z}}\right)-\varepsilon_{\gamma}^{\mathrm{H}}\left(\overrightarrow{\mathrm{k}}_{\mathrm{z}}\right)-\hbar \omega_{\lambda, \overrightarrow{\mathrm{q}}_{\mathrm{z}}}-\mathrm{g} \hbar \Omega+\mathrm{i} \hbar \delta\right)\left(\mathrm{t}-\mathrm{t}^{\prime}\right)\right\}- \\
& -\left[\mathrm{n}_{\gamma^{\prime}, \overrightarrow{\mathrm{z}}_{\mathrm{z}}-\overrightarrow{\mathrm{q}}_{\mathrm{z}}}\left(\mathrm{t}^{\prime}\right) \cdot\left(\mathrm{N}_{\lambda, \mathrm{q}_{\mathrm{z}}}+1\right)-\mathrm{n}_{\gamma, \overrightarrow{\mathrm{k}}_{\mathrm{z}}}\left(\mathrm{t}^{\prime}\right) \cdot \mathrm{N}_{\lambda, \mathrm{q}_{\mathrm{z}}}\right] \times \\
& \times \exp \left\{\mathrm{i}\left(\varepsilon_{\gamma}^{\mathrm{H}}\left(\overrightarrow{\mathrm{k}}_{\mathrm{z}}\right)-\varepsilon_{\gamma^{\prime}}^{\mathrm{H}}\left(\overrightarrow{\mathrm{k}}_{\mathrm{z}}-\overrightarrow{\mathrm{q}}_{\mathrm{z}}\right)+\hbar \omega_{\lambda, \overrightarrow{\mathrm{q}}_{\mathrm{z}}}-\mathrm{g} \hbar \Omega+\mathrm{i} \hbar \delta\right)\left(\mathrm{t}-\mathrm{t}^{\prime}\right)\right\}- \\
& -\left[\mathrm{n}_{\gamma^{\prime}, \overrightarrow{\mathrm{k}}_{\mathrm{z}}-\overrightarrow{\mathrm{q}}_{\mathrm{z}}}\left(\mathrm{t}^{\prime}\right) \cdot \mathrm{N}_{\lambda, \overrightarrow{\mathrm{q}}_{\mathrm{z}}}-\mathrm{n}_{\gamma, \overrightarrow{\mathrm{k}}_{\mathrm{z}}}\left(\mathrm{t}^{\prime}\right) \cdot\left(\mathrm{N}_{\lambda, \overrightarrow{\mathrm{q}}_{\mathrm{z}}}+1\right)\right] \times \\
& \left.\times \exp \left\{\mathrm{i}\left(\varepsilon_{\gamma}^{\mathrm{H}}\left(\overrightarrow{\mathrm{k}}_{\mathrm{z}}\right)-\varepsilon_{\gamma^{\prime}}^{\mathrm{H}}\left(\overrightarrow{\mathrm{k}}_{\mathrm{z}}-\overrightarrow{\mathrm{q}}_{\mathrm{z}}\right)-\hbar \omega_{\lambda, \overrightarrow{\mathrm{q}}_{\mathrm{z}}}-\mathrm{g} \hbar \Omega+\mathrm{i} \hbar \delta\right)\left(\mathrm{t}-\mathrm{t}^{\prime}\right)\right\}\right\}
\end{aligned}
$$

where $\mathrm{J}_{\mathrm{g}}(\mathrm{x})$ is the Bessel function, $\mathrm{m}$ is the effective mass of the electron, $\mathrm{N}_{\lambda, \overline{\mathrm{q}}_{\mathrm{z}}}$ is the time independent component of the phonon distribution function, $\mathrm{n}_{\gamma, \vec{k}_{z}}(t)$ is electron distribution function in cylindrical quantum wire and the quantity $\delta$ is infinitesimal and appears due to the assumption of an adiabatic interaction of the electromagnetic wave; $\gamma=\mathrm{n}, \ell, \mathrm{N} ; \gamma^{\prime}=\mathrm{n}^{\prime}, \ell^{\prime}, \mathrm{N}^{\prime} ; \lambda=\mathrm{m}, \mathrm{k}$.

It is well known that to obtain the explicit solutions from Eq. (25) is very difficult. In this paper, we use the first - order tautology approximation method (Pavlovich \& Epshtein, 1977; Malevich \& Epstein, 1974; Epstein, 1975) to solve this equation. In detail, in Eq. (25), we use the approximation: $\mathrm{n}_{\gamma, \overrightarrow{\mathrm{k}}_{\mathrm{z}}}\left(\mathrm{t}^{\prime}\right) \approx \overline{\mathrm{n}}_{\gamma, \overrightarrow{\mathrm{k}}_{\mathrm{z}}} ; \mathrm{n}_{\gamma^{\prime}, \overrightarrow{\mathrm{k}}_{\mathrm{z}} \pm \overline{\mathrm{q}}_{\mathrm{z}}}\left(\mathrm{t}^{\prime}\right) \approx \overline{\mathrm{n}}_{\gamma^{\prime}, \overrightarrow{\mathrm{k}}_{\mathrm{z}} \pm \overrightarrow{\mathrm{q}}_{\mathrm{z}}}$.

where $\bar{n}_{\gamma, \bar{k}_{z}}$ is the time - independent component of the electron distribution function in cylindrical quantum wire. The approximation is also applied for a similar exercise in bulk semiconductors (Pavlovich \& Epshtein, 1977; Malevich \& Epstein, 1974). We perform the integral with respect to $t$. Next, we perform the integral with respect to $t$ of Eq. (25). The expression of electron distribution function can be written as:

$$
\begin{aligned}
& \mathrm{n}_{\gamma, \overrightarrow{\mathrm{k}}_{\mathrm{z}}}(\mathrm{t})=-\sum_{\gamma^{\prime}, \overrightarrow{\mathrm{q}}_{\mathrm{z}}} \sum_{\lambda}\left|\mathrm{C}_{\overrightarrow{\mathrm{q}}_{\mathrm{z}}}^{\lambda}\right|^{2} \cdot\left|\mathrm{I}_{\mathrm{n} \ell, \mathrm{n}^{\prime} \ell^{\prime}}^{\lambda}\right|^{2} \cdot\left|\mathrm{J}_{\mathrm{N}, \mathrm{N}^{\prime}}\right|^{2} \sum_{\mathrm{g}, \mathrm{s}=-\infty}^{+\infty} \mathrm{J}_{\mathrm{g}}\left(\frac{\mathrm{e} \overrightarrow{\mathrm{E}}_{\mathrm{o}} \overrightarrow{\mathrm{q}}}{\mathrm{m}^{*} \Omega^{2}}\right) \cdot \mathrm{J}_{\mathrm{g}+\mathrm{s}}\left(\frac{\mathrm{e} \overrightarrow{\mathrm{E}}_{\mathrm{o}} \overrightarrow{\mathrm{q}}}{\mathrm{m}^{*} \Omega^{2}}\right) \cdot \frac{\exp (-\mathrm{is} \Omega \mathrm{t})}{\mathrm{s} \Omega} \times \\
& \times\left\{-\frac{\overline{\mathrm{n}}_{\gamma, \overrightarrow{\mathrm{k}}_{\mathrm{z}}} \cdot \mathrm{N}_{\lambda, \overrightarrow{\mathrm{q}}_{\mathrm{z}}}-\overline{\mathrm{n}}_{\gamma^{\prime}, \overrightarrow{\mathrm{z}}_{\mathrm{z}}} \cdot\left(\mathrm{N}_{\lambda, \overrightarrow{\mathrm{q}}_{\mathrm{z}}}+1\right)}{\varepsilon_{\gamma^{\prime}}^{\mathrm{H}}\left(\overrightarrow{\mathrm{k}}_{\mathrm{z}}+\overrightarrow{\mathrm{q}}_{\mathrm{z}}\right)-\varepsilon_{\gamma}^{\mathrm{H}}\left(\overrightarrow{\mathrm{k}}_{\mathrm{z}}\right)-\hbar \omega_{\lambda, \overrightarrow{\mathrm{q}}_{z}}-\mathrm{g} \hbar \Omega+\mathrm{i} \hbar \delta}-\frac{\overline{\mathrm{n}}_{\gamma, \overrightarrow{\mathrm{k}}_{\mathrm{z}}} \cdot\left(\mathrm{N}_{\lambda, \overrightarrow{\mathrm{q}}_{z}}+1\right)-\overline{\mathrm{n}}_{\gamma^{\prime}, \overrightarrow{\mathrm{k}}_{\mathrm{z}}+\overrightarrow{\mathrm{q}}_{z}} \cdot \mathrm{N}_{\lambda, \overrightarrow{\mathrm{q}}_{z}}}{\varepsilon_{\gamma^{\prime}}^{\mathrm{H}}\left(\overrightarrow{\mathrm{k}}_{\mathrm{z}}+\overrightarrow{\mathrm{q}}_{\mathrm{z}}\right)-\varepsilon_{\gamma}^{\mathrm{H}}\left(\overrightarrow{\mathrm{k}}_{\mathrm{z}}\right)+\hbar \omega_{\lambda, \overrightarrow{\mathrm{q}}_{\mathrm{z}}}-\mathrm{g} \hbar \Omega+\mathrm{i} \hbar \delta}+\right. \\
& \left.+\frac{\overline{\mathrm{n}}_{\gamma^{\prime} \overrightarrow{\mathrm{k}}_{z}-\overrightarrow{\mathrm{q}}_{\mathrm{z}}} \cdot \mathrm{N}_{\lambda, \overrightarrow{\mathrm{q}}_{\mathrm{z}}}-\overline{\mathrm{n}}_{\gamma, \overrightarrow{\mathrm{k}}_{\mathrm{z}}} \cdot\left(\mathrm{N}_{\lambda, \overrightarrow{\mathrm{q}}_{\mathrm{z}}}+1\right)}{\varepsilon_{\gamma}^{\mathrm{H}}\left(\overrightarrow{\mathrm{k}}_{\mathrm{z}}\right)-\varepsilon_{\gamma^{\prime}}^{\mathrm{H}}\left(\overrightarrow{\mathrm{k}}_{\mathrm{z}}-\overrightarrow{\mathrm{q}}_{\mathrm{z}}\right)-\hbar \omega_{\lambda, \overrightarrow{\mathrm{q}}_{\mathrm{z}}}-\mathrm{g} \hbar \Omega+\mathrm{i} \hbar \delta}+\frac{\overline{\mathrm{n}}_{\gamma^{\prime} \overrightarrow{\mathrm{k}}_{\mathrm{z}}-\overrightarrow{\mathrm{q}}_{\mathrm{z}}} \cdot\left(\mathrm{N}_{\lambda, \mathrm{q}_{\mathrm{z}}}+1\right)-\overline{\mathrm{n}}_{\gamma, \mathrm{k}_{\mathrm{z}}} \cdot \mathrm{N}_{\lambda, \overrightarrow{\mathrm{q}}_{\mathrm{z}}}}{\varepsilon_{\gamma}^{\mathrm{H}}\left(\overrightarrow{\mathrm{k}}_{\mathrm{z}}\right)-\varepsilon_{\gamma^{\prime}}^{\mathrm{H}}\left(\overrightarrow{\mathrm{k}}_{\mathrm{z}}-\overrightarrow{\mathrm{q}}_{\mathrm{z}}\right)+\hbar \omega_{\lambda, \overrightarrow{\mathrm{q}}_{\mathrm{z}}}-\mathrm{g} \hbar \Omega+\mathrm{i} \hbar \delta}\right\}
\end{aligned}
$$


From Eq.(26) we see that the electron distribution function depends on the constant in the case of confined electron - confined phonon interaction, the electron form factor and the electron energy spectrum in cylindrical quantum wire. Eq.(26) also can be considered a general expression of the electron distribution function in cylindrical quantum wire with the electron form factor and the electron energy spectrum of each systems.

\subsection{Calculations of the nonlinear absorption coefficient of a strong electromagnetic wave by confined electrons in a cylindrical quantum wire in the presence of a magnetic field with case of confined phonons}

The nonlinear absorption coefficient of a strong electromagnetic wave $\alpha$ in a cylindrical quantum wire take the form similary to Eq.(9):

$$
\alpha=\frac{8 \pi}{c \sqrt{\chi_{\infty}} E_{o}^{2}}\left\langle\vec{j}_{z}(t) \vec{E}_{o} \sin \Omega t\right\rangle_{t}
$$

where $\langle X\rangle_{t}$ means the usual thermodynamic average of $X$ at moment $t, \vec{A}(t)$ is the vector potential, $\mathrm{E}_{\mathrm{o}}$ and $\Omega$ is the intensity and frequency of electromagnetic wave. The carrier current density formula in a cylindrical quantum wire takes the form similary to in (Pavlovich \& Epshtein, 1977):

$$
\overrightarrow{\mathrm{j}}_{\mathrm{z}}(\mathrm{t})=\frac{\mathrm{e} \hbar}{\mathrm{m}^{*}} \sum_{\gamma, \overrightarrow{\mathrm{k}}_{\mathrm{z}}}\left(\overrightarrow{\mathrm{k}}_{\mathrm{z}}-\frac{\mathrm{e}}{\mathrm{c}} \overrightarrow{\mathrm{A}}(\mathrm{t})\right) \cdot \mathrm{n}_{\gamma, \overrightarrow{\mathrm{k}}_{\mathrm{z}}}(\mathrm{t})
$$

Because the motion of electrons is confined along the $(x, y)$ direction in a cylindrical quantum wire, we only consider the in - plane $z$ current density vector of electrons, $\overrightarrow{\mathrm{j}}_{\mathrm{z}}(\mathrm{t})$. Using Eq. (28), we find the expression for current density vector:

$$
\overrightarrow{\mathrm{j}}_{\mathrm{z}}(\mathrm{t})=-\frac{\mathrm{e}^{2} \hbar \mathrm{n}_{\mathrm{o}}^{*} \cdot \overrightarrow{\mathrm{E}}_{\mathrm{o}}}{\mathrm{m}^{*} \Omega} \cos (\Omega \mathrm{t})+\frac{\mathrm{e} \hbar}{\mathrm{m}^{*}} \sum_{\gamma, \overrightarrow{\mathrm{k}}_{\mathrm{z}}} \overrightarrow{\mathrm{k}}_{\mathrm{z}} \cdot \mathrm{n}_{\gamma, \overrightarrow{\mathrm{k}}_{\mathrm{z}}}(\mathrm{t})
$$

We insert the expression of $n_{\gamma, \bar{k}_{z}}(t)$ into the expression of $\vec{j}_{z}(t)$ and then insert the expression of $\vec{j}_{2}(t)$ into the expression of $\alpha$ in Eq.(27). Using property of Bessel function $\mathrm{J}_{\mathrm{k}+1}(\mathrm{x})+\mathrm{J}_{\mathrm{k}-1}(\mathrm{x})=2 \mathrm{~kJ}_{\mathrm{k}}(\mathrm{x}) / \mathrm{x}$, and realizing calculations, we obtain the nonlinear absorption coeffcient of a strong electromagnetic wave by confined electrons in cylindrical quantum wire with case of confined phonons:

$$
\begin{array}{r}
\alpha=\frac{4 \pi^{3} \cdot \mathrm{e}^{2} \cdot \Omega \cdot \mathrm{k}_{\mathrm{B}} \cdot \mathrm{T}}{\varepsilon_{\mathrm{o}} \cdot \mathrm{c} \sqrt{\chi_{\infty}} \mathrm{E}_{\mathrm{o}}^{2} \cdot V}\left(\frac{1}{\chi_{\infty}}-\frac{1}{\chi_{0}}\right) \sum_{\gamma, \gamma^{\prime}, \lambda} \sum_{\mathrm{q}_{\mathrm{z}}, \overrightarrow{\mathrm{k}}_{\mathrm{z}}} \sum_{\mathrm{g}=-\infty}^{+\infty}\left|\mathrm{C}_{\mathrm{q}_{\mathrm{z}}}^{\lambda}\right|^{2} \cdot\left|\mathrm{I}_{\mathrm{n} \ell, \mathrm{n}^{\prime} \ell^{\prime}}^{\lambda}\right|^{2} \cdot\left|\mathrm{J}_{\mathrm{N}, \mathrm{N}^{\prime}}\right|^{2} \cdot \mathrm{k} \cdot \mathrm{J}_{\mathrm{g}}^{2}\left(\frac{\mathrm{e} \overrightarrow{\mathrm{E}}_{\mathrm{o}} \overrightarrow{\mathrm{q}}}{\mathrm{m}^{*} \Omega^{2}}\right) \times \\
\times \frac{1}{\mathrm{q}_{\mathrm{z}}{ }^{2}+\mathrm{q}_{\lambda}^{2}} \times\left(\overline{\mathrm{n}}_{\gamma, \overrightarrow{\mathrm{k}}_{\mathrm{z}}}-\overline{\mathrm{n}}_{\gamma^{\prime}, \overrightarrow{\mathrm{k}}_{\mathrm{z}}+\overrightarrow{\mathrm{q}}_{\mathrm{z}}}\right) \cdot \delta\left(\varepsilon_{\gamma^{\prime}}^{\mathrm{H}}\left(\overrightarrow{\mathrm{k}}_{\mathrm{z}}+\overrightarrow{\mathrm{q}}_{\mathrm{z}}\right)-\varepsilon_{\gamma}^{\mathrm{H}}\left(\overrightarrow{\mathrm{k}}_{\mathrm{z}}\right)+\omega_{\mathrm{o}}-\mathrm{g} \Omega\right)
\end{array}
$$

We only consider the absorption close to its threshold because in the rest case (the absorption far away from its threshold) $\alpha$ is very smaller. In the case, the condition $\left|\mathrm{g} \Omega-\omega_{\mathrm{o}}\right|<<\bar{\varepsilon}$ must be satisfied (Pavlovich \& Epshtein, 1977). We restrict the problem to the case of one photon absorption and consider the electron gas to be non-degenerate: 


$$
\bar{n}_{\gamma, \vec{k}_{z}}=n_{o}^{*} \cdot \exp \left\{-\frac{\varepsilon_{\gamma_{,},_{z}}}{k_{B} T}\right\} \text {, with } n_{o}^{*}=\frac{n_{o}(\pi e)^{3 / 2}}{V\left(m_{o} k_{B} T\right)^{3 / 2}}
$$

By using the electron - optical phonon interaction factor, the Bessel function and the electron distribution function, from the general expression for the nonlinear absorption coefficient of a strong electromagnetic wave in a cylindrical quantum wire Eq.(30), we obtain the explicit expression of the nonlinear absorption coefficient $\alpha$ in cylindrical quantum wire for the case confined electron-confined optical phonon scattering:

$$
\begin{aligned}
\alpha= & \frac{\mathrm{e}^{4} \cdot \mathrm{n}_{0}^{*} \cdot \Omega_{\mathrm{B}} \cdot \mathrm{k}_{\mathrm{B}} \mathrm{T}}{4 \sqrt{2} \cdot \varepsilon_{\mathrm{o}} \cdot \mathrm{c} \sqrt{\chi_{\infty}} \mathrm{m}^{*} \cdot \mathrm{a}_{\mathrm{c}} \cdot \Omega^{3} \cdot \mathrm{V}} \times\left(\frac{1}{\chi_{\infty}}-\frac{1}{\chi_{\mathrm{o}}}\right) \sum_{\gamma, \gamma^{\prime}, \lambda}\left|\mathrm{I}_{\mathrm{n}, \ell, \mathrm{n}^{\prime}, \ell^{\prime}}^{\lambda}\right|^{2} \cdot\left(\frac{\mathrm{N}_{\mathrm{n}} !}{\mathrm{N}_{\mathrm{m}} !}\right) \times \\
& \times\left[\exp \left\{-\frac{\Omega_{\mathrm{B}}}{\mathrm{k}_{\mathrm{B}} \mathrm{T}}\left(\mathrm{N}+\frac{\mathrm{n}}{2}+\frac{1}{2}+\frac{|\ell|}{2}\right)\right\}-\exp \left\{-\frac{\Omega_{\mathrm{B}}}{\mathrm{k}_{\mathrm{B}} \mathrm{T}}\left(\mathrm{N}^{\prime}+\frac{\mathrm{n}^{\prime}}{2}+\frac{1}{2}+\frac{\ell^{\prime} \mid}{2}\right)\right\} \times\right. \\
& \times \sum_{\mathrm{M}=0}^{+\infty}(-1)^{\mathrm{M}}\left(\frac{1}{2} \mathrm{a}_{\mathrm{c}}^{2} \mathrm{q}_{\lambda}^{2}\right)^{\mathrm{M}} \times\left\{\mathrm{C}_{1}(\mathrm{M})+\frac{1}{\mathrm{a}_{\mathrm{c}}^{2}}\left(\frac{\mathrm{eE_{0 }}}{2 \mathrm{~m}^{*} \Omega^{2}}\right)^{2} \cdot \mathrm{C}_{2}(\mathrm{M})\right\} \times \frac{\sqrt{\mathrm{A}_{\mathrm{QR}}|\mathrm{Q}|}}{\mathrm{Q}\left(\Omega-\omega_{0}+\mathrm{M} \Omega_{\mathrm{B}}\right)^{2}+\mathrm{A}_{\mathrm{QR}}}
\end{aligned}
$$

Where $C_{1}(M), C_{2}(M)$ are functions of $M$ :

$$
\begin{aligned}
& \mathrm{C}_{1}(\mathrm{M})=\frac{\Gamma\left(\mathrm{N}_{\mathrm{m}}-\mathrm{N}_{\mathrm{n}}-\mathrm{M}+\frac{1}{2}\right) \Gamma\left(1+\mathrm{N}_{\mathrm{m}}\right)}{\left(\mathrm{N}_{\mathrm{n}} !\right)^{2} \Gamma\left(1+\mathrm{N}_{\mathrm{m}}-\mathrm{N}_{\mathrm{n}}\right)} \times \\
& \times\left\{\frac{d^{N_{n}}}{\mathrm{dh}^{N_{n}}}\left[\frac{F\left(\frac{N_{m}-N_{n}-M+\frac{1}{2}}{2} ; \frac{N_{m}-N_{n}-M+\frac{3}{2}}{2} ; 1+N_{m}-N_{n} ; \frac{4 h}{(1-h)^{2}}\right)}{(1-h)^{M+\frac{1}{2}} \cdot(1+h)^{N_{m}-N_{n}-M+\frac{1}{2}}}\right]\right\} \\
& \mathrm{C}_{2}(\mathrm{M})=\frac{\Gamma\left(\mathrm{N}_{\mathrm{m}}-\mathrm{N}_{\mathrm{n}}-\mathrm{M}+\frac{3}{2}\right) \cdot \Gamma\left(1+\mathrm{N}_{\mathrm{m}}\right)}{\left(\mathrm{N}_{\mathrm{n}} !\right)^{2} \cdot \Gamma\left(1+\mathrm{N}_{\mathrm{m}}-\mathrm{N}_{\mathrm{n}}\right)} \times
\end{aligned}
$$

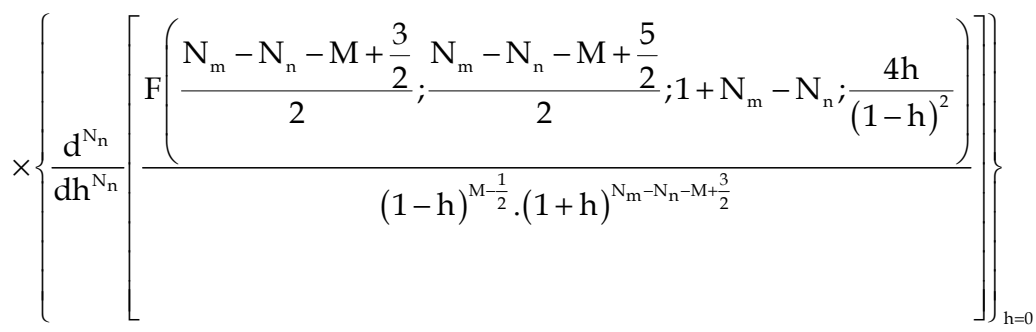

and $\mathrm{A}_{\mathrm{QR}}$ is written as: 


$$
\begin{gathered}
\mathrm{A}_{\mathrm{QR}}=\frac{\mathrm{e}^{2} \mathrm{k}_{\mathrm{B}} \mathrm{T}}{8 \pi^{2} \varepsilon_{\mathrm{o}} \mathrm{V}}\left|\mathrm{I}_{\mathrm{n} \ell, \mathrm{n}^{\prime} \ell^{\prime}}^{\lambda}\right|^{2}\left(\frac{1}{\chi_{\infty}}-\frac{1}{\chi_{\mathrm{o}}}\right) ; \mathrm{Q}=\left[\mathrm{N}-\mathrm{N}^{\prime}+\frac{\mathrm{n}-\mathrm{n}^{\prime}}{2}+\frac{|\ell|-\left|\ell^{\prime}\right|}{2}\right] ; \\
\mathrm{N}_{\mathrm{n}}:=\min \left\{\mathrm{N}, \mathrm{N}^{\prime}\right\} ; \mathrm{N}_{\mathrm{m}}:=\max \left\{\mathrm{N}^{\prime}, \mathrm{N}^{\prime}\right\}
\end{gathered}
$$

From analytic expressions of the nonlinear absorption coefficient of a strong electromagnetic wave by confined electrons in cylindrical quantum wire with infinite potential in the presence of a magnetic field (Eq.31), we can see that quantum numbers $(\mathrm{m}, \mathrm{k})$ characterizing confined phonons reaches to zero, the result of nonlinear absorption coefficient will turn back to the case of unconfined phonons (Bau \& Trien, 2010):

$$
\begin{aligned}
\alpha= & \frac{\mathrm{e}^{4} \cdot \mathrm{n}_{0}^{*} \cdot \Omega_{\mathrm{B}} \cdot \mathrm{k}_{\mathrm{B}} \mathrm{T}}{2 \varepsilon_{\mathrm{o}} \cdot \mathrm{c} \cdot \sqrt{\chi_{\infty}} \cdot \mathrm{V}_{\mathrm{o}} \cdot \mathrm{m}^{*} \cdot \mathrm{a}_{\mathrm{c}}^{2} \cdot \Omega^{3}}\left(\frac{1}{\chi_{\infty}}-\frac{1}{\chi_{0}}\right) \sum_{\substack{\mathrm{n}, \prime^{\prime}, \mathrm{N}^{\prime} \\
\mathrm{n}^{\prime}, \ell^{\prime}, \mathrm{N}^{\prime}}} \frac{\mathrm{N}_{\mathrm{m}} !}{\mathrm{N}_{\mathrm{n}} !} \times \\
\times & {\left[\exp \left\{-\frac{\Omega_{\mathrm{B}}}{\mathrm{k}_{\mathrm{B}} \mathrm{T}}\left(\mathrm{N}+\frac{\mathrm{n}}{2}+\frac{1}{2}+\frac{\ell \mid}{2}\right)\right\}-\exp \left\{-\frac{\Omega_{\mathrm{B}}}{\mathrm{k}_{\mathrm{B}} \mathrm{T}}\left(\mathrm{N}^{\prime}+\frac{\mathrm{n}^{\prime}}{2}+\frac{1}{2}+\frac{\left|\ell^{\prime}\right|}{2}\right)\right\}\right] \times } \\
& \times\left[1+\left(\mathrm{N}_{\mathrm{m}}+\mathrm{N}_{\mathrm{n}}+1\right) \frac{3}{4 \mathrm{a}_{\mathrm{c}}^{2}}\left(\frac{\mathrm{e} \cdot \mathrm{E}_{\mathrm{o}}}{2 \mathrm{~m}^{*} \Omega^{2}}\right)^{2}\right] \frac{\sqrt{\mathrm{A}|\mathrm{M}|}}{\mathrm{M}\left(\Omega-\omega_{\mathrm{o}}+\mathrm{M} \Omega_{\mathrm{B}}\right)^{2}+\mathrm{A}}
\end{aligned}
$$

with $\mathrm{A}=\frac{\mathrm{e}^{2} \mathrm{k}_{\mathrm{B}} \mathrm{T}}{8 \pi^{2} \varepsilon_{\mathrm{o}} \mathrm{V}}\left|\mathrm{I}_{\mathrm{n} \ell, \mathrm{n}^{\prime} \ell^{\prime}}\right|^{2}\left(\frac{1}{\chi_{\infty}}-\frac{1}{\chi_{\mathrm{o}}}\right) ;$ which $\mathrm{I}_{\mathrm{n} \ell, \mathrm{n}^{\prime} \ell^{\prime}}$ is written as in (Bau \& Trien, 2010)

\subsection{Numerical results and discussion}

In order to clarify the results that have been obtained, in this section, we numerically calculate the nonlinear absorption coefficient of a strong electromagnetic wave for a $\mathrm{GaAs}=\mathrm{GaAsAl}$ cylindrical quantum wire. The nonlinear absorption coefficient is considered as a function of the intensity $E_{o}$ and energy of strong electronmagnet wave, the temperature $\mathrm{T}$ of the system, and the parameters of cylindrical quantum wire. The parameters used in the numerical calculations (Bau\&Trien, 2010) are $\varepsilon_{0}=12.5, \chi_{\infty}=10.9, \chi_{0}=13.1, m=0.066 m_{0}, m_{0}$ being the mass of free electron, $\hbar \omega_{o} \approx \hbar \omega_{\mathrm{m}, \mathrm{k}, \mathrm{q}_{z}}=36.25 \mathrm{meV}, \mathrm{k}_{\mathrm{B}}=1.3807 \times 10-23 \mathrm{j} / \mathrm{K}, \mathrm{n}_{\mathrm{o}}=10^{23} \mathrm{~m}^{-}$ $3, \mathrm{e}=1.60219 \times 10^{-19} \mathrm{C}, \mathrm{h}=1.05459 \times 10^{-34} \mathrm{j} / \mathrm{s}$.

Fig. $(13,14)$ shows the dependence of nonlinear absorption coefficient of a strong electromagnetic wave on the radius of wire. It can be seen from this figure that a depends strongly and nonlinear on the radius of wire but it does not have the maximum value (peak), the absorption increases when $\mathrm{R}$ is reduced. This is different from the case of the absence of a magnetic field. Fig. (13) show clearly the strong effect of confined phonons on the nonlinear absorption coefficient, It decreases faster in case of confined phonons.

Fig. (15) presents the dependence of nonlinear absorption coefficient on the electromagnetic wave energy at different values of the temperature $\mathrm{T}$ of the system. It is shown that nonlinear absorption coefficient depends much strongly on photon energy but the spectrum quite different from case of unconfined phonons (Bau\&Trien, 2010). Namely, there are more resonant peaks appearing than in case of unconfined phonons and the values of resonant peaks are higher. These sharp peaks are demonstrated that the nonlinear absorption 
coefficient only significant when there is the condition. This means that a depends strongly on the frequency $\Omega$ of the electromagnetic wave.

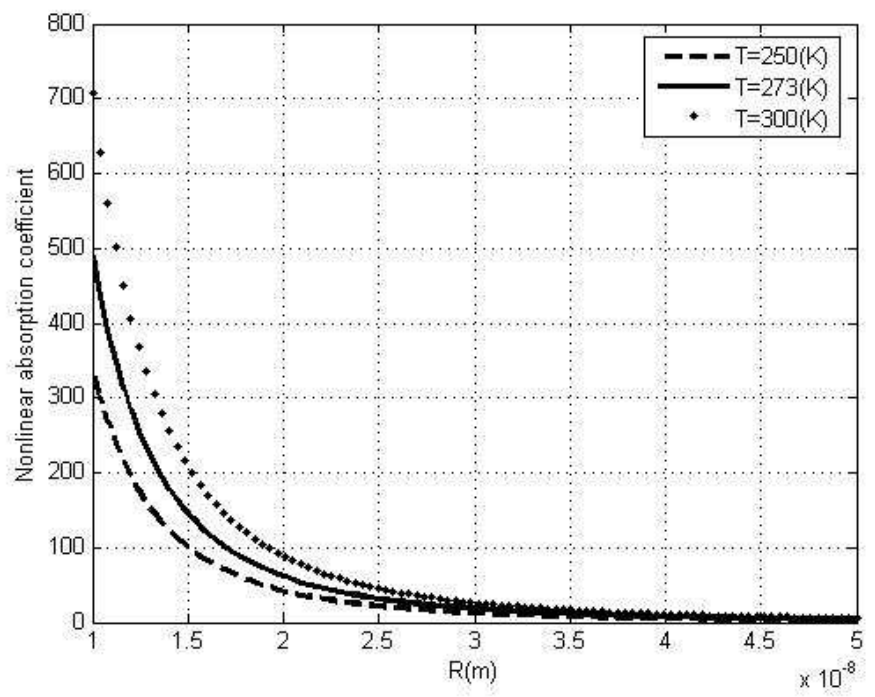

Fig. 13. The dependence of nonlinear absorption coefficient on $\mathrm{R}$ and $\mathrm{T}$ in case of confined phonons

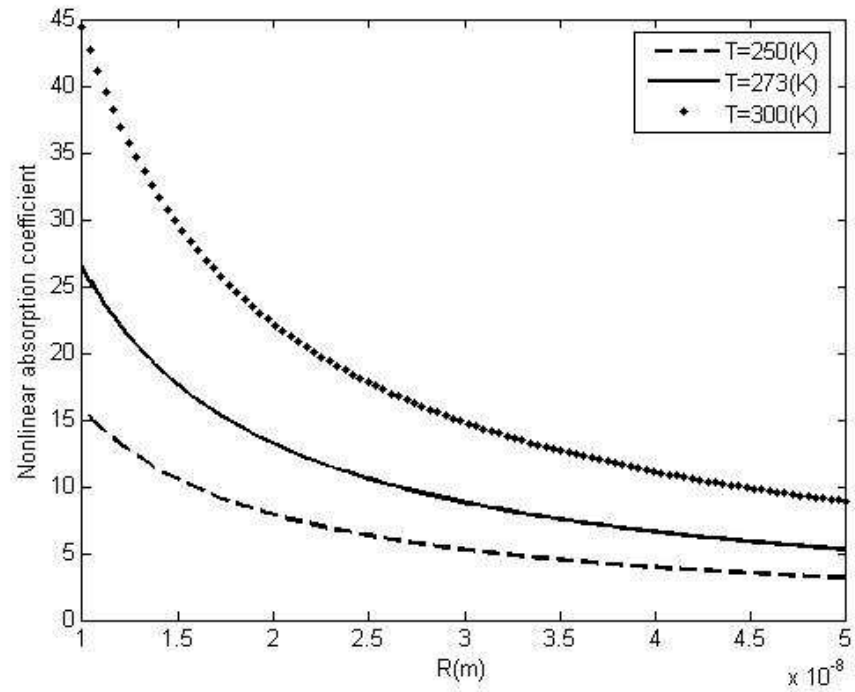

Fig. 14. The dependence of nonlinear absorption coefficient on $\mathrm{R}$ and $\mathrm{T}$ in case of unconfined phonons 


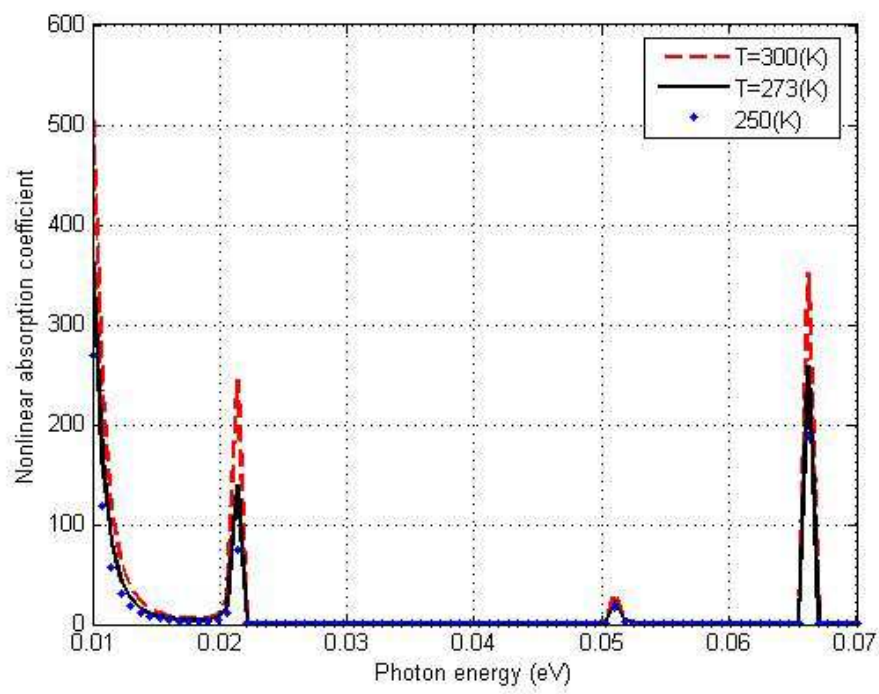

Fig. 15. The dependence of nonlinear absorption coefficient on $\hbar \Omega$ and $\mathrm{T}$ in case confined phonons

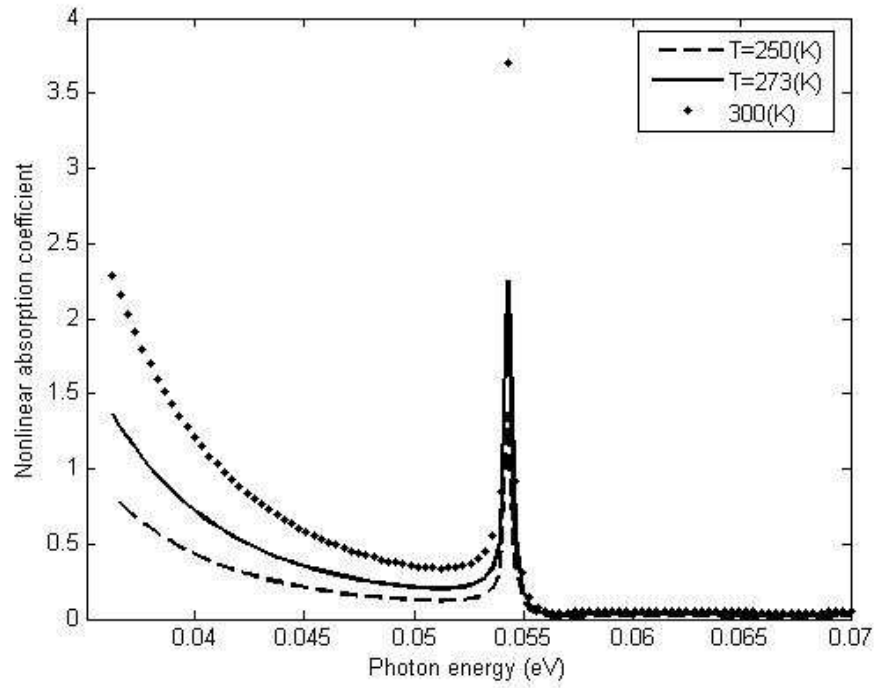

Fig. 16. The dependence of nonlinear absorption coefficient on $\hbar \Omega$ and $\mathrm{T}$ in case unconfined phonons

It can be seen from this figure that nonlinear absorption coefficient depends strongly and nonlinearly on $\mathrm{T}$, $\mathrm{a}$ is stronger at large values of the temperature $\mathrm{T}$. 


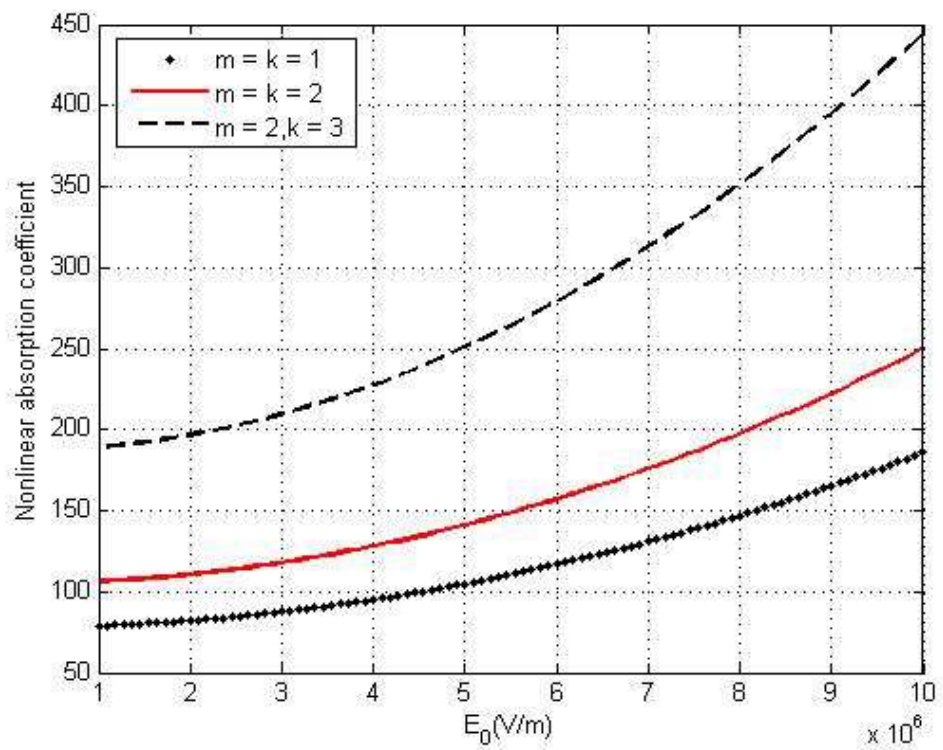

Fig. 17. The dependence of nonlinear absorption coefficient on $\mathrm{R}$ and $\mathrm{m}, \mathrm{k}$ in case confined phonons

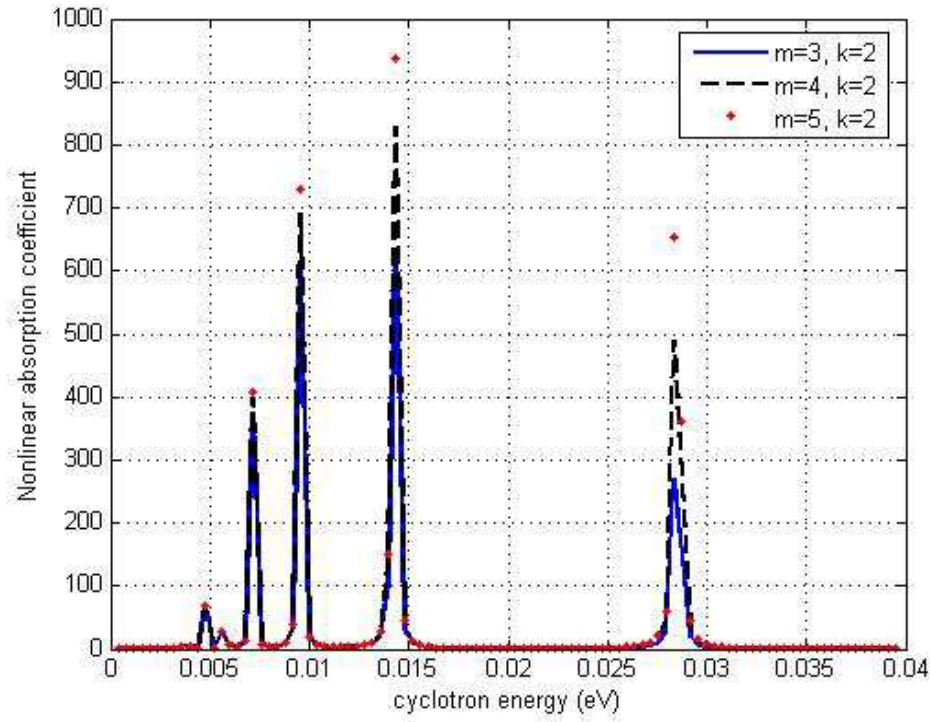

Fig. 18. The dependence of nonlinear absorption coefficient on $\hbar \Omega_{B}$ and $\mathrm{m}, \mathrm{k}$ in case confined phonons 
Fig. 17 shows the dependence of nonlinear absorption coefficient on intensity $E_{0}$ of electromagnetic wave in case confined phonons. It can be seen from this figure that $a$ depends strongly and nonlinearly on $E_{0}$. $\alpha$ is stronger at large values of the intensity $E_{0}$ of electromagnetic wave.

Fig. 18 presents the dependence of $a$ on the cyclotron energy $\left(\hbar \Omega_{B}\right)$ of the magnetic field. It can be seen from this figure that there are same resonance peaks at different values of cyclotron frequency $\hbar \Omega_{B}$. The nonlinear absorption coefficient only significant at these resonance peaks. Based on this result we make the following remarks: The index of Landau level $\mathrm{N}^{\prime}$ which electrons can move to after absorption. Only at these peaks, strong electromagnetic wave is absorbed strongly. In addition, the density of resonance peaks is very high in the region where $\Omega_{\mathrm{B}}<\Omega$, corresponding to the weak magnetic field $\overrightarrow{\mathrm{B}}$, but this density is low when $\vec{B}$ increases. These resonance peaks, reflect the effect of quantum magnetic field on the quantum wire. When the magnetic field is stronger, the peaks is more discrete, the influence of the magnetic field is shown more clearly.

Fig. $(17,18)$ show that nonlinear absorption coefficient depends much strongly on quantum numbers characterizing confined phonons $(\mathrm{m}, \mathrm{k})$, it increases fllowing $(\mathrm{m}, \mathrm{k})$. It mean that the confined phonons have huge effect on nonlinear absorption coefficient of a strong electromagnetic wave in cylindrical quantum wire.

\section{Conclusion}

In this chapter, the nonlinear absorption of a strong electromagnetic wave by confined electrons in low-dimensional systems in the presence of an external magnetic field is investigated. By using the method of the quantum kinetic equation for electrons, the expressions for the electron distribution function and the nonlinear absorption coefficient in quantum wells, doped superlattics, cylindrical quantum under the influence of an external magnetic field are obtained. The analytic results show that the nonlinear absorption coefficient depends on the intensity $\mathrm{E}_{0}$ and the frequency $\Omega$ of the external strong electromagnetic wave, the temperature $\mathrm{T}$ of the system, the cyclotron frequency, the quantum number characterizing confined phonons and the parameters of the lowdimensional systems as the width $L$ of quantum well, the doping concentration $n_{D}$ in doped superlattices, the radius $\mathrm{R}$ of cylindrical quantum wires. This dependence are complex and has difference from those obtained in case unconfined phonon and absence of an external magnetic field (Pavlovich \& Epshtein, 1977), the expressions for the nonlinear absorption coefficient has the sum over the quantum number of confined electron-confined optical phonon and contain the cyclotron frequency. All expressions for the nonlinear absorption coefficient turn back to case of unconfined phonon and absence of an external magnetic field if the quantum number and the cyclotron frequency reaches to zero.

The numerical results obtained for a AlAs/GaAs/AlAs quantum well, a n-GaAs/p-GaAs doped superlattice, a GaAs/GaAsAl cylindrical quantum show that a depends strongly and nonlinearly on the intensity $\mathrm{E}_{0}$ and the frequency $\Omega$ of the external strong electromagnetic wave, the temperature $\mathrm{T}$ of the system, the cyclotron frequency, the quantum number characterizing confined phonons and the parameters of the low-dimensional systems. The numerical results shows that the confinement effect and the presence of an external magnetic field in low dimensional systems has changed significantly the nonlinear absorption coefficient. The spectrums of the nonlinear absorption coefficient have changed 
in value, densty of resononlinear absorption coefficiente peaks, position of resononlinear absorption coefficiente peaks. Namely, the values of nonlinear absorption coefficient is much higher, densty of resononlinear absorption coefficiente peaks is bigger.

In addition, from the analytic results, we see that when the term in proportion to a quadratic in the intensity of the electromagnetic wave $\left(\mathrm{E}_{\mathrm{o}}\right)$ (in the expressions for the nonlinear absorption coefficient of a strong electromagnetic wave) tend toward zero, the nonlinear result will turn back to a linear result (Bau \& Phong, 1998; Bau et al., 2002; 2007).

The nonlinear absorption in each low-dimensional systems in the presence of an external magnetic field is also quite different, for example, the nonlinear absorption coefficient in quantum wires is bigger than those in quantum wells and doped superlattices.

\section{Acknowledgment}

This work is completed with financial support from the Vietnam National Foundation for Science and Technology Development (Vietnam NAFOSTED).

\section{References}

Abouelaoualim,D.(1992). Electron-confined LO-phonon scattering in GaAs- $A l_{0.45} \mathrm{Ga}_{0.55} \mathrm{As}$ superlattice, Pramana Journal of physics, Vol.66, pp. 455-465, ISSN 0304-4289, Available from www.ias.ac.in/pramana/v66/p455/fulltext.pdf

Bau, N.Q. \& Trien, H.D. (2011). The Nonlinear Absorption of a Strong Electromagnetic Wave in Low-dimensional Systems, Intech: Wave Propagation, chaper 22, pp. 461482, ISBN 978-953-307-275-3, Available from www.intechopen.com/download/pdf/pdfs_id/14174

Bau, N. Q.; Hung, L. T. \& Nam, N. D. (2010). The Nonlinear Absorption Coefficient of a Strong Electromagnetic Wave by Confined Electrons in Quantum Wells under the Influences of Confined Phonons, J. of Electromagn. Waves and Appl., Vol.24, pp. 1751-1761, ISSN 0920-5071, ISSN(Online) 1569-3937, Available from

http:/ / www.ingentaconnect.com/content/vsp/jew/2010/00000024/00000013/art 00006

Bau, N.Q. \& Trien, H.D. (2010). The Nonlinear Absorption Coefficient of Strong Electromagnetic Waves Caused by Electrons Confined in Quantum Wires, J. Korean Phys. Soc, Vol. 56, pp. 120-127, ISSN 0374-4884, Available from http://www.kps.or.kr/home/kor/journal/library/downloadPdf.asp?articleuid= \%7B26781ED0-F7CB-42A7-8C64-152F89D300B5\%7D

Bau, N. Q. \& Trien,H.D. (2010). The nonlinear absorption of a strong electromagnetic wave by confined electrons in rectangular quantum wires, PIERS Proceedings (March 22-26), pp. 336-341, ISSN 1559-9450, Available from http:// piers.org/ piersproceedings/piers2010XianProc.php?searchname=Bau

Bau,N.Q.; Hung,M.D.\&Hung,.L.T. (2010). The influences of confined phonons on the nonlinear absorption coefficient of a strong electromagnetic wave by confined electrons in doping superlattices, Pier Letters, Vol. 15, pp. 175-185, ISSN 1937-6480, Available from www.jpier.org/PIERL/pierl15/20.10030911.pdf

Bau N.Q.; Hung, N.M. \& Ngoc ,N.B. (2009). The Nonlinear Absorption Coeffcient of a Strong Electromagnetic Wave Caused by Conffined Electrons in Quantum Wells, J. Korean. Phys. Soc, Vol. 42, No.2, pp. 765-773, ISSN 0374-4884 
Bau,N.Q.; Dinh,L.\& Phong,T.C(2007). Absorption coefficient of weak electromagnetic waves caused by confined electrons in quantum wires, J. Korean.Phys. Soc., Vol. 51, pp. 13251330, ISSN 0374-4884, Available from http://www.kps.or.kr/jkps/downloadPdf.asp?articleuid=\%7B9BAB8518-F80B41F5-A49D-5407B4614DD9\%7D

Bau, N. Q. and Phong, T. C. (1998). Calculations of the Absorption Coefficient of a Weak Electromagnetic Wave by free Carriers in Quantum Wells by the Kubo-Mori Method, J.Phys. Soc. Japan, Vol. 67, pp. 3875-3880, , ISSN 0031-9015, ISSN(Online) 1347-4073

Bau, N.Q.; Nhan, N.V. \&Phong, T.C. (2002). Calculations of the absorption coefficient of a weak electromagnetic wave by free carriers in doped superlattices by using the Kubo - Mori method, J. Korean. Phys. Soc., Vol. 41, pp. 149-154, ISSN 0374-4884, Available from http://www.kps.or.kr/home/kor/journal/library/downloadPdf.asp?articleuid= \%7BD05E09B1-B3AA-4AFD-9748-1D4055F885DB\%7D

Butscher.S.\& Knorr,A.(2006). Occurrence of Intersubband Polaronic Repellons in a TwoDimensional Electron Gas, Phys. Rev. L, Vol. 97, pp. 197401-197405, ISSN 0031-9007, ISSN(Online) 1079-7114, Available from http://prl.aps.org/abstract/PRL/v97/i19/e197401

Chaubey, M.P.\& Carolyn, M. (1986). Transverse magnetoconductivity of quasi-two-dimensional semiconductor layers in the presence of phonon scattering, Phys. Rev. B, Vol.33, pp. 5617-5622, ISSN 1098-0121, ISSN(Online) 1550-235X, Available from http://prb.aps.org/abstract/PRB/v33/i8/p5617_1

Flores, A. D. A.(2008). Electron subband structure and mobility trends in $p$-n delta-doped quantum wells in Si, Pier Letters, Vol. 1, pp. 159-165, ISSN: 1937-6480, Available from www.jpier.org/PIERL/pier101/19.07120607.pdf

Generazio, E.R.\& Spector.H.N. (1979). Free-carrier absorption in quantizing magnetic fields, Phys. Rev. B, Vol. 20, pp. 5162-5167, ISSN 1098-0121, ISSN(Online) 1550-235X, Available from http:// prb.aps.org/abstract/PRB/v20/i12/p5162_1

Richter, M.; Carmele, A.; Butscher, S.; Bücking, N.; F. Milde.; Kratzer P.; Scheffler M. \& Knorr, A. (2009). Two-dimensional electron gases: Theory of ultrafast dynamics of electron-phonon interactions in graphene, surfaces, and quantum wells, J. Appl. Phys., Vol. 105, pp. 122409-122416, Print: ISSN 0021-8979, ISSN(Online) 1089-7550, Available from http://jap.aip.org/japiau/v105/i12/p122409_s1?bypassSSO=1

Li ,W. S.; Gu, S.W.; Au-Yeung, T. C.\& Yeung,Y. Y. (1992). Effects of the parabolic potential and confined phonons on the polaron in a quantum wire, Phys. Rev. B, Vol.46,pp. 4630-4637, Available from http://prb.aps.org/abstract/PRB/v46/i8/p4630_1

Malevich, V. L. \& Epstein, E. M. (1974). Nonlinear optical properties of conduction electrons in semiconductors, Sov. Quantum Electronic, Vol. 4, p. 816, ISSN: 0049-1748, Available from http://iopscience.iop.org/0049-1748/4/6/L27

Sager, L.M.G.; Martine, N. M.; Vargas I. R.; Alvarez, R. Pe.; Grimalsky,V. V.\& Mora Ramos,M. E.(2007). Electronic structure as a function of temperature for Si doped quantum wells in GaAs, PIERS Online, Vol. 3, No. 6, pp. 851-854, ISSN 1931-7360, Available from www.jpier.org/PIERL/ pier101/19.07120607.pdf

Mori, N. and Ando, T. (1989). Electron-optical-phonon interaction in single and double heterostructures, Phys. Rev.B, Vol.40, pp. 6175-6188, ISSN: 1937-6480, Available from http://prb.aps.org/abstract/PRB/v40/i9/p6175_1 
Pavlovich, V. V. \& Epshtein, E. M. (1977). Quantum theory of absorption of electronmagnetic wave by free carries in simiconductors, Sov. Phys. Solid State., Vol.19, pp. 1760, ISSN: 0038-5654

Ryu, J.Y.\& O'Connell, R. F. (1993). Magnetophonon resonances in quasi-one-dimensional quantum wires, Phys. Rev. B, Vol. 48, pp. 9126-9129, ISSN 1098-0121, ISSN(Online) 1550235X, Available from http://prb.aps.org/abstract/PRB/v48/i12/p9126_1

Rucker ,H.; Molinari ,E. \& Lugli, P.(1992). Microscopic calculation of the electron-phonon interaction in quantum wells, Phys. Rev. B, Vol. 45, pp. 6747-6756, ISSN 1098-0121, ISSN(Online) 1550-235X, Available from http://prb.aps.org/abstract/PRB/v45/i12/p6747_1

Samuel, E. P.,\& Patil, D. S. (2008). Analysis of wavefunction distribution in quantum well biased laser diode using transfer matrix method, Pier Letters, Vol. 1, pp. 119-128, ISSN: 19376480, Available from www.jpier.org/PIERL/pier101/15.07111902.pdf

Suzuki, A.(1992). Theory of hot-electron magneto phonon resonance in quasi-two-dimensional quantum-well structures, Phys. Rev. B, Vol.45, pp. 6731-6741, ISSN 1098-0121, ISSN(Online) 1550-235X, Available from http://prb.aps.org/abstract/PRB/v45/i12/p6731_1

Shmelev,G. M. ; Chaikovskii, L. A. \& Bau ,N. Q. (1978). HF conduction in semiconductors superlattices, Soc. Phys. Tech. Semicond, Vol. 12, No.10, p. 1932, ISSN 0018-9383

Vasilopoulos,P. M.; Charbonneau\& Vliet,C.M.Van(1987). Linear and nonlinear electrical conduction in quasi-two-dimensional quantum wells, Phys. Rev. B, Vol. 35, pp. 13341344, ISSN 1098-0121, ISSN(Online) 1550-235X, Available from http://prb.aps.org/abstract/PRB/v45/i12/p6731_1

Yu, Y.B.; Guo, K.X. \& Zhu. S.N.(2005). Polaron influence on the third-order nonlinear optical susceptibility in cylindrical quantum wires, Physica E, Vol. 27, pp. 62-66, ISSN: 13869477, Available from http://adsabs.harvard.edu/abs/2005PhyE...27...62Y

Wang,X. F. \& Lei, X. L. (1994). The polar-optic phonons and high field electron transport in cylindrical GaAs/AlAs quantum wires, Phys. Rev. B, Vol. 49, pp. 4780-4789, ISSN 10980121, ISSN(Online) 1550-235X, http:/ / prb.aps.org/abstract/PRB/v49/i7/p4780_1 


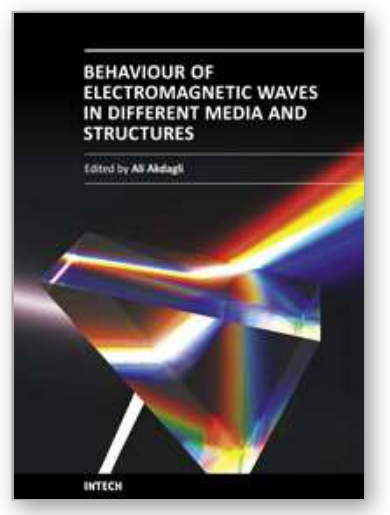

\author{
Behaviour of Electromagnetic Waves in Different Media and \\ Structures \\ Edited by Prof. Ali Akdagli
}

ISBN 978-953-307-302-6

Hard cover, 440 pages

Publisher InTech

Published online 09, June, 2011

Published in print edition June, 2011

This comprehensive volume thoroughly covers wave propagation behaviors and computational techniques for electromagnetic waves in different complex media. The chapter authors describe powerful and sophisticated analytic and numerical methods to solve their specific electromagnetic problems for complex media and geometries as well. This book will be of interest to electromagnetics and microwave engineers, physicists and scientists.

\title{
How to reference
}

In order to correctly reference this scholarly work, feel free to copy and paste the following:

Nguyen Quang Bau, Le Thai Hung and Hoang Dinh Trien (2011). Effect of Magnetic Field on Nonlinear Absorption of a Strong Electromagnetic Wave in Low-dimensional Systems, Behaviour of Electromagnetic Waves in Different Media and Structures, Prof. Ali Akdagli (Ed.), ISBN: 978-953-307-302-6, InTech, Available from: http://www.intechopen.com/books/behavior-of-electromagnetic-waves-in-different-media-andstructures/effect-of-magnetic-field-on-nonlinear-absorption-of-a-strong-electromagnetic-wave-in-lowdimensiona1

\section{INTECH}

open science | open minds

\section{InTech Europe}

University Campus STeP Ri Slavka Krautzeka 83/A 51000 Rijeka, Croatia Phone: +385 (51) 770447 Fax: +385 (51) 686166 www.intechopen.com

\section{InTech China}

Unit 405, Office Block, Hotel Equatorial Shanghai No.65, Yan An Road (West), Shanghai, 200040, China 中国上海市延安西路65号上海国际贵都大饭店办公楼405单元 Phone: +86-21-62489820

Fax: +86-21-62489821 
(C) 2011 The Author(s). Licensee IntechOpen. This chapter is distributed under the terms of the Creative Commons Attribution-NonCommercialShareAlike-3.0 License, which permits use, distribution and reproduction for non-commercial purposes, provided the original is properly cited and derivative works building on this content are distributed under the same license. 